ARTICLE

\title{
Proton-assisted calcium-ion storage in aromatic organic molecular crystal with coplanar stacked structure
}

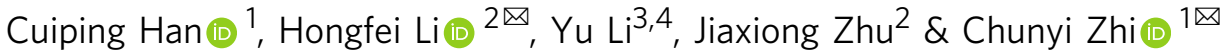

Rechargeable calcium-ion batteries are intriguing alternatives for use as post-lithium-ion batteries. However, the high charge density of divalent $\mathrm{Ca}^{2+}$ establishes a strong electrostatic interaction with the hosting lattice, which results in low-capacity Ca-ion storage. The ionic radius of $\mathrm{Ca}^{2+}$ further leads to sluggish ionic diffusion, hindering high-rate capability performances. Here, we report 5,7,12,14-pentacenetetrone (PT) as an organic crystal electrode active material for aqueous Ca-ion storage. The weak $\pi-\pi$ stacked layers of the PT molecules render a flexible and robust structure suitable for Ca-ion storage. In addition, the channels within the PT crystal provide efficient pathways for fast ionic diffusion. The PT anode exhibits large specific capacity $\left(150.5 \mathrm{mAh} \mathrm{g}^{-1}\right.$ at $\left.5 \mathrm{~A} \mathrm{~g}^{-1}\right)$, high-rate capability (86.1 $\mathrm{mAh} \mathrm{g}^{-1}$ at $100 \mathrm{Ag}^{-1}$ ) and favorable low-temperature performances. A mechanistic study identifies proton-assisted uptake/removal of $\mathrm{Ca}^{2+}$ in PT during cycling. First principle calculations suggest that the Ca ions tend to stay in the interstitial space of the PT channels and are stabilized by carbonyls from adjacent PT molecules. Finally, pairing with a high-voltage positive electrode, a full aqueous Ca-ion cell is assembled and tested.

\footnotetext{
${ }^{1}$ Department of Materials Science and Engineering, City University of Hong Kong, Kowloon, Hong Kong, China. ${ }^{2}$ Songshan Lake Materials Laboratory, Dongguan, Guangdong, China. ${ }^{3}$ College of Materials Science and Engineering, Shenzhen University, Shenzhen, China. ${ }^{4}$ Shenzhen Key Laboratory of Special Functional Materials, Shenzhen University, Shenzhen, China. ${ }^{凶}$ email: lihf@sslab.org.cn; cy.zhi@cityu.edu.hk
} 
ecently, a flurry of research activity has been devoted to developing alternative battery technologies in addition to lithium-ion batteries (LIBs) based on earth-abundant elements ${ }^{1-4}$. Rechargeable calcium-ion batteries (CIBs) can offer considerable advantages including cost-effectiveness and high volumetric/gravimetric capacity $\left(2072 \mathrm{mAh} \mathrm{mL}^{-1}\right.$ and $\left.1337 \mathrm{mAh} \mathrm{g}^{-1}\right)^{5}$ due to their high abundance and a relatively lower reduction potential (i.e., $-2.87 \mathrm{~V},-2.37 \mathrm{~V}$, and $-1.66 \mathrm{~V}$ vs. SHE for $\mathrm{Ca} / \mathrm{Ca}^{2+}, \mathrm{Mg} / \mathrm{Mg}^{2+}$, and $\mathrm{Al} / \mathrm{Al}^{3+}$, respectively) ${ }^{6}$ and the divalent electron redox properties of calcium ${ }^{7}$. However, current research on CIBs is still in its infancy because the reversible plating/stripping of metallic calcium is possible only with judiciously tailored nonaqueous electrolytes ${ }^{8-11}$. Moreover, severe undesired side reactions accompany the deposition of calcium, such as the formation of $\mathrm{CaF}_{2}, \mathrm{CaCl}_{2}, \mathrm{CaCO}_{3}$, and $\mathrm{CaH}_{2}$, leading to low Columbic efficiency and continuous growth of a passivation film on the calcium electrode surface ${ }^{8,12,13}$. The complexity of working directly with a Ca-metal anode drives the need for alternative anode materials. Another challenge of CIBs, both nonaqueous and aqueous, is the absence of high-performance electrode materials. The high charge density and the relatively large ionic radius of divalent $\mathrm{Ca}^{2+}(0.099 \mathrm{~nm})$ make these ions interact more strongly with the hosting lattice than monovalent cations, which results in sluggish $\mathrm{Ca}^{2+}$ ion diffusion in inorganic crystals $^{14}$. For example, Rong et al. investigated the migration of several multivalent ions $\left(\mathrm{Mg}^{2+}, \mathrm{Zn}^{2+}, \mathrm{Ca}^{2+}\right.$, and $\left.\mathrm{Al}^{3+}\right)$ in spinel $\mathrm{Mn}_{2} \mathrm{O}_{4}$, olivine $\mathrm{FePO}_{4}$, layered $\mathrm{NiO}_{2}$, and orthorhombic $\delta-\mathrm{V}_{2} \mathrm{O}_{5}$ and found that the mobility of multivalent ions is consistently lower than that of $\mathrm{Li}^{+}$. Furthermore, the barrier of different bivalent ions depends greatly on the hosting structure ${ }^{15}$. High multivalent ion mobility in solids is only possible by judicious tuning of crystal structure and chemistry ${ }^{16}$. However, to date, only a handful of anode materials have been demonstrated, and the best-known anode materials are Sn-based alloys ${ }^{17,18}$ and graphite $^{19}$. Their performances, especially the specific capacity and cycling stability, are still far from satisfactory. The specific capacities of the reported CIBs fade rapidly to the best of our knowledge, and the cycling life barely exceeds 1000 cycles. Therefore, the exploration of electrode candidates capable of reversible $\mathrm{Ca}^{2+}$ ion storage is critically important for the development of CIBs.

Advantageously, organic solids are assembled by weak van der Waals forces, which endow them with a more flexible solid structure and low repulsion for $\mathrm{Ca}$ ion diffusion. Moreover, organic materials show the merits of high abundance, high electrochemical reactivity, and large structural diversity. Thus, they are promising candidate electrodes for electrochemical energy storage applications ${ }^{20-22}$. Unfortunately, little attention has been given to the exploration of $\mathrm{Ca}^{2+}$-hosting organic electrodes, and reports of their performance is very limited ${ }^{23-26}$. Organic solids with planar structures and efficient diffusion pathways are highly favorable for facilitating the storage and diffusion of charge-dense and bulky $\mathrm{Ca}^{2+}$ ions. In this regard, aromatic organic crystals, made of molecules that contain benzene ring subunits, are potential electrodes for high-rate CIBs due to their readily formed channels and voids in the molecules. To date, the organic aromatic molecule family of crystals has remained unexplored for CIBs. More importantly, little understanding has been gained on the storage chemistry or structural evolution of organic materials during multivalent ion storage, including $\mathrm{Ca}^{2+}$ storage. Therefore, it is vital to search for highperformance aromatic organic crystals and clarify their detailed charge storage process, including their reactive sites, molecular structural changes and possible side reactions (e.g., the coinsertion of proton or decomposition of the electrolyte solvent).
Here, we report aromatic organic molecular crystals, represented by 5,7,12,14-pentacenetetrone (PT), as a high-rate and long-life CIB anode material in mild aqueous electrolytes. The aromatic PT molecules are bonded with van der Waals forces, forming a coplanar stacked layered structure with rich $1 \mathrm{D}$ channels perpendicular to the molecular layers. The flexible structure of organic materials and the presence of 1D channels facilitate the reversible uptake/removal of charge-dense $\mathrm{Ca}$ ions, providing a diffusion coefficient on the order of $10^{-8}-10^{-11} \mathrm{~S} \mathrm{~cm}^{-1}$. As expected, the PT anode exhibits promising $\mathrm{Ca}$ ion storage performance, including a high discharge capacity of $150.5 \mathrm{~mA} \mathrm{~h} \mathrm{~g}^{-1}$ at $5 \mathrm{~A} \mathrm{~g}^{-1}$, superior retained rate capacity of $86.1 \mathrm{~mA} \mathrm{~h} \mathrm{~g}^{-1}$ at a large specific current of $100 \mathrm{~A} \mathrm{~g}^{-1}$, and good capacity retention at low temperature. A mechanistic study revealed that protons in aqueous electrolytes significantly contribute to the $\mathrm{Ca}$ ion storage and that the highly reversible chemical adsorption and desorption of both protons and $\mathrm{Ca}^{2+}$ with carbonyl groups comprise the dominant redox reaction ${ }^{27}$. Furthermore, theoretical calculations reveal that the negative charges of Ca-based enolate are delocalized across the stacks due to $\pi-\pi$ stacking interactions such that one $\mathrm{Ca}^{2+}$ ion is stabilized by four carbonyls from adjacent PT molecules. Finally, an aqueous full $\mathrm{Ca}$-ion cell is prepared by pairing the PT-based electrode with a $\mathrm{KCoFe}(\mathrm{CN})_{6} \bullet \mathrm{xH}_{2} \mathrm{O}$ cathode, rendering a high voltage of $2.1 \mathrm{~V}$ and good capacity performance. These findings contribute to understanding the charge storage behavior of organic electrode materials.

\section{Results and discussion}

Several organic aromatic molecular crystals with different numbers of aromatic rings and carbonyl groups at different positions were selected and compared, including 2,5-dichloro-1,4-benzoquinone (2,5-dichloro BQ), 2,5-dimethoxybenzo-1,4-quinone (DMQ), 1,5-dichloro-anthraquinone (1,5-dichloro AQ), phenanthrenequinone $(9,10-\mathrm{PQ})$, perylene-3,4,9,10-tetracarboxylic dianhydride (PTCDA), and PT. All the selected electrodes are feasible for studying highly reversible $\mathrm{Ca}^{2+}$ ion uptake in an aqueous $\mathrm{CaCl}_{2}$ electrolyte. Generally, organic compound redox properties are directly related to their chemical structure and can be tuned through judicious incorporation of appropriate functionalities. Aromatic organic molecules with fewer electrondonating phenyl groups $\left(-\mathrm{C}_{6} \mathrm{H}_{5}\right)$, such as DMQ and 2,5-dichloro $\mathrm{BQ}$, show relatively higher redox potentials (Fig. 1a). However, their capacity is limited to $40-60 \mathrm{~mA} \mathrm{~h} \mathrm{~g}^{-1}$, most likely due to the high charge density of $\mathrm{Ca}^{2+}$, causing strong electrostatic repulsion from the small molecules. PT displays relatively low redox potential and exciting specific capacity values with a large aromatic ring and a high carbonyl group concentration, making it a promising anode material for aqueous CIBs. Structural and morphological characterizations were first determined on the PT material. The XRD profile shows a series of distinct peaks at $2 \theta=$ $8^{\circ}, 12^{\circ}, 13.4^{\circ}, 15.4^{\circ}, 20.8^{\circ}, 22.2^{\circ}, 24.3^{\circ}$, and $28.2^{\circ}$, with $d$ spacing of $1.1,0.74,0.65,0.57,0.43,0.40,0.37$, and $0.32 \mathrm{~nm}$, respectively (Fig. 1b). The presence of strong diffraction peaks confirms the highly crystalline nature of PT as an aromatic organic molecular crystal, which is different from conventional amorphous organic materials. Rietveld refinement was then applied to the XRD profile, and a triclinic lattice with $P \overline{1}$ symmetry and cell parameters of $a=0.476 \mathrm{~nm}, b=0.754 \mathrm{~nm}, c=1.112 \mathrm{~nm}, \alpha=97.68^{\circ}$, $\beta=93.23^{\circ}$, and $\gamma=99.13^{\circ}$ was obtained (Supplementary Table 1). According to the refined crystal structure, all PT molecules are uniformly aligned, forming a coplanar packed motif (Fig. 1c) ${ }^{28}$. Perpendicular to this coplanar direction, the PT molecules are $\pi-$ $\pi$ stacked layer-by-layer, forming 1D molecular channels (pink circles in Fig. 1c) that are walled by the adjacent PT molecules. 

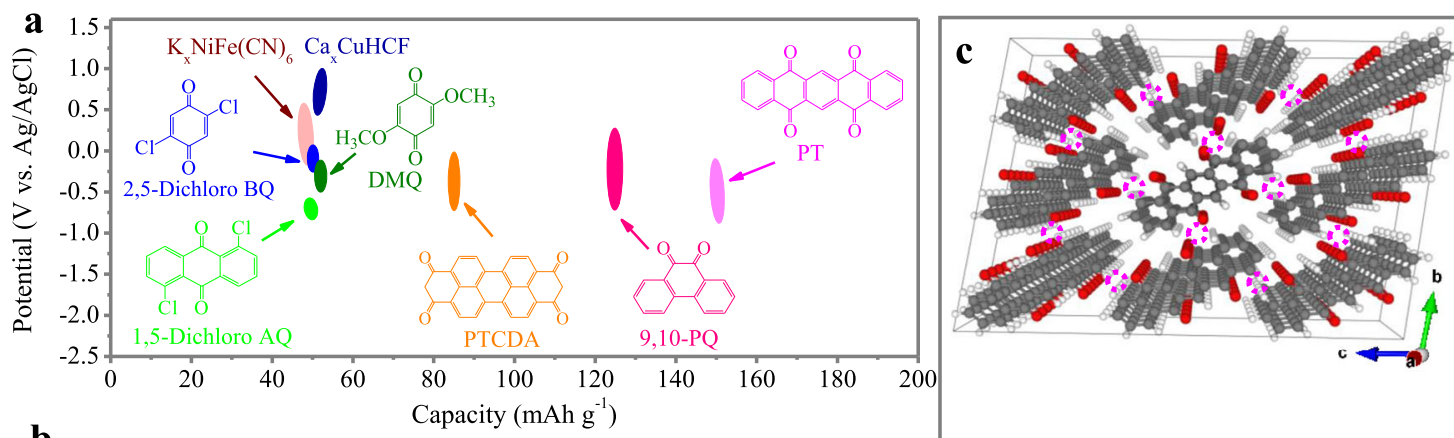

b
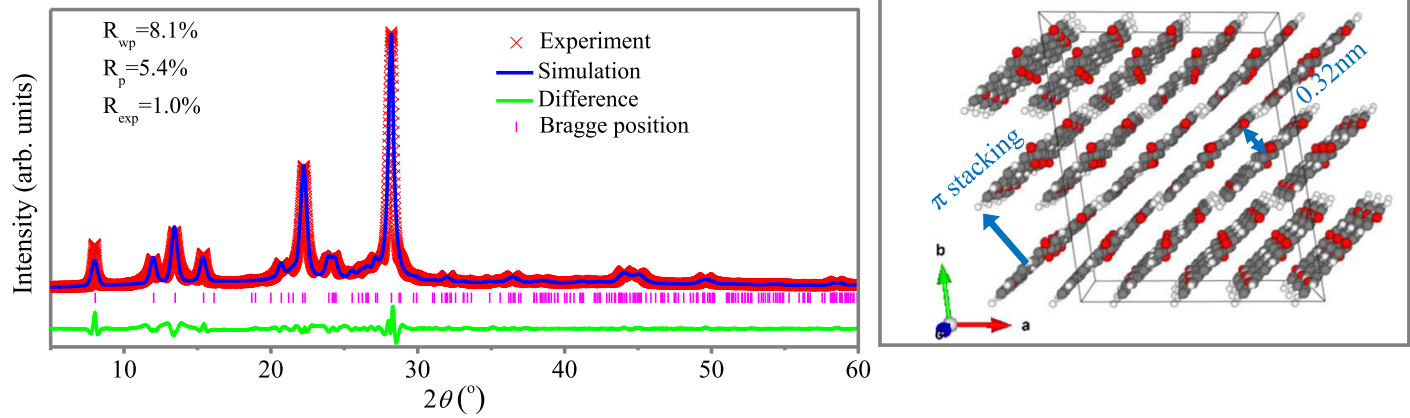
$2 \theta\left(^{\circ}\right)$
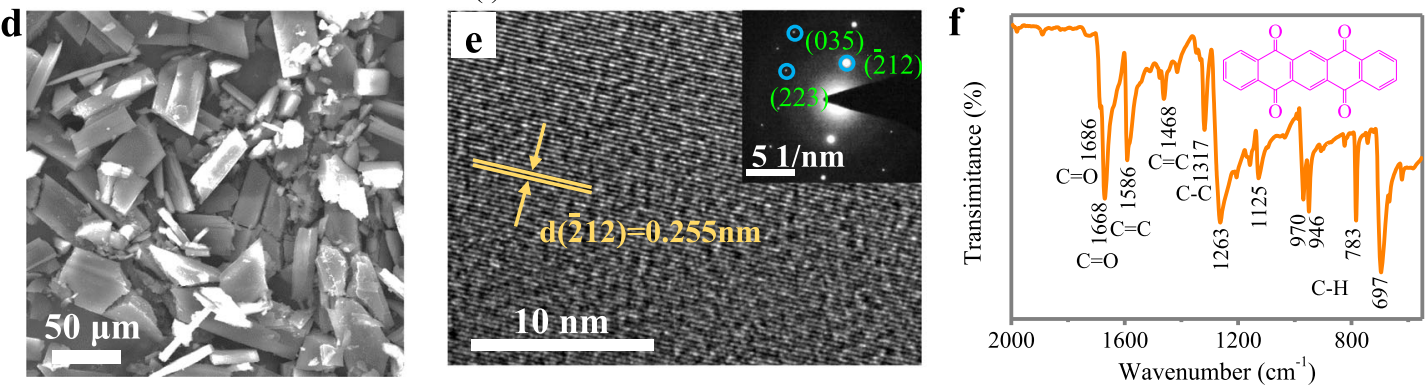

Fig. 1 Comparison of selected aromatic organic molecular crystals and structural characterization of the PT materials. a Discharge/charge voltage ranges and capacities of selected aromatic organic molecular crystals (DMQ, 2,5-dichloro $B Q, 1,5$-dichloro $A Q, 9,10-P Q, P T C D A$, and PT in $1 M$ CaCl 2 electrolyte. The typically reported inorganic electrodes including $\mathrm{Ca}_{x} \mathrm{CuHCF}^{32}, \mathrm{~K}_{x} \mathrm{NiFe}(\mathrm{CN})_{6} 33$, are also listed for comparison. $\mathbf{b}$ XRD pattern of $\mathrm{PT}$ powder (red cross) and the Rietveld-refined XRD pattern (blue line). c Perspective view of a PT supercell observed from a axis and $\mathrm{c}$ axis. $\mathbf{d}$ SEM image. e HRTEM image and SAED pattern. $\mathbf{f}$ FTIR spectrum of PT materials.

The existence of these $1 \mathrm{D}$ channels is expected to facilitate the diffusion of $\mathrm{Ca}$ ions within the PT crystal. The interplanar distance is $\sim 0.32 \mathrm{~nm}$, which is very close to the interlayer spacing in graphite. The morphological observation reveals that pure PT materials are microsized rods with $50-80 \mu \mathrm{m}$ in length and 20-40 $\mu \mathrm{m}$ in width (Fig. 1d). High-resolution transition electron microscopy was also used to confirm the crystalline nature. Lattice fringes of the $(\overline{2} 12)$ space group with a $d$ spacing of $0.255 \mathrm{~nm}$ and the corresponding selected-area electron diffraction (SAED) patterns were observed (Fig. 1e). Then, the functional groups of PT were revealed by Fourier transform infrared (FTIR) spectroscopy (Fig. 1f). Specifically, characteristic peaks at approximately 1686 and $1668 \mathrm{~cm}^{-1}$ can be assigned to the stretching vibration of carbonyl groups ${ }^{29,30}$. The strong adsorption bands at 1586 and $1468 \mathrm{~cm}^{-1}$ represent the stretching vibration of $\mathrm{C}=\mathrm{C}$ bonds in the aromatic ring ${ }^{30}$. The peak at $1317 \mathrm{~cm}^{-1}$ is assigned to the $\mathrm{C}-\mathrm{C}$ stretching vibration. The peaks at 1263 and $1125 \mathrm{~cm}^{-1}$ can be attributed to $\mathrm{C}-\mathrm{H}$ in-plane bending vibrations while the peaks at $970,946,783$, and $697 \mathrm{~cm}^{-1}$ are attributed to $\mathrm{C}-\mathrm{H}$ out-of-plane bending vibrations in the aromatic ring ${ }^{31}$.

To evaluate the electrochemical property of the PT crystal as $\mathrm{Ca}^{2+}$ ion-hosting materials, cyclic voltammetry (CV) profiles were first recorded at $20 \mathrm{mV} \mathrm{s}^{-1}$ in $1 \mathrm{M} \mathrm{CaCl}_{2}$ aqueous solution using three-electrode configuration (Fig. 2a, Supplementary Fig. 1). The initial CV curve of the PT anode displays two reduction peaks at $-0.3 \mathrm{~V},-0.66 \mathrm{~V}$ vs. $\mathrm{Ag} / \mathrm{AgCl}$ and three oxidization peaks at $-0.47 \mathrm{~V},-0.38 \mathrm{~V}$, and $-0.2 \mathrm{~V}$ vs. $\mathrm{Ag} / \mathrm{AgCl}$ under $20 \mathrm{mV} \mathrm{s}^{-1}$, respectively. The presence of multiple peaks suggests stepwise and multiple electron transfer during the $\mathrm{Ca}^{2+}$ insertion and extraction process. Interestingly, the subsequent $\mathrm{CV}$ curves are slightly different from the initial curve. The cathodic peak at $-0.3 \mathrm{~V}$ vs. $\mathrm{Ag} / \mathrm{AgCl}$ disappears in the following cycles, due to the reduction of dissolved $\mathrm{O}_{2}$ in the electrolyte, as shown in Supplementary Fig. 2. Moreover, the reduction peak at $-0.66 \mathrm{~V}$ slightly shifts to $-0.63 \mathrm{~V}$ and is gradually amplified with increasing cycle number. In addition, a shoulder reduction peak at $-0.85 \mathrm{~V}$ progressively emerged. In the anodic process, the gradual increase in peak intensity and the presence of an additional shoulder peak at $-0.76 \mathrm{~V}$ were also observed, all suggesting the activation of PT during repeated $\mathrm{Ca}^{2+}$ storage. This activation process is most likely related to the morphological evolution of large PT bulks to small nanowires as discussed in a subsequent section, leading to the gradual exposure of inner active surface but also contributes to fast ion diffusion and efficient charge transfer due to better accessibility for charge carriers infiltrating into the cathode materials. The origin of each peak is discussed in a subsequent section.

The following galvanostatic charge/discharge (GCD) test further revealed the promising electrochemical performance of the PT anode. At an initial specific current of $5 \mathrm{Ag}^{-1}$, a gradual 

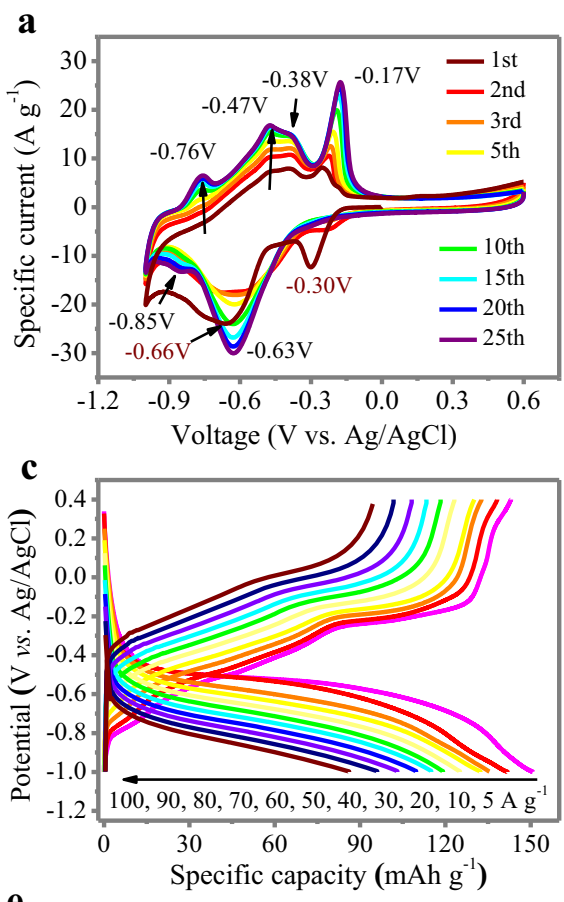

e

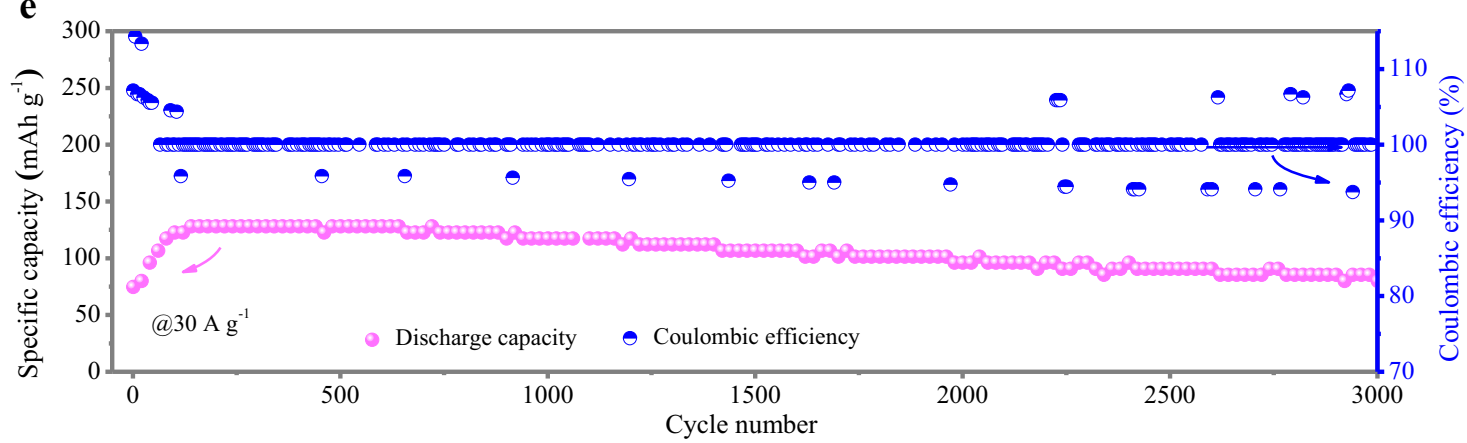

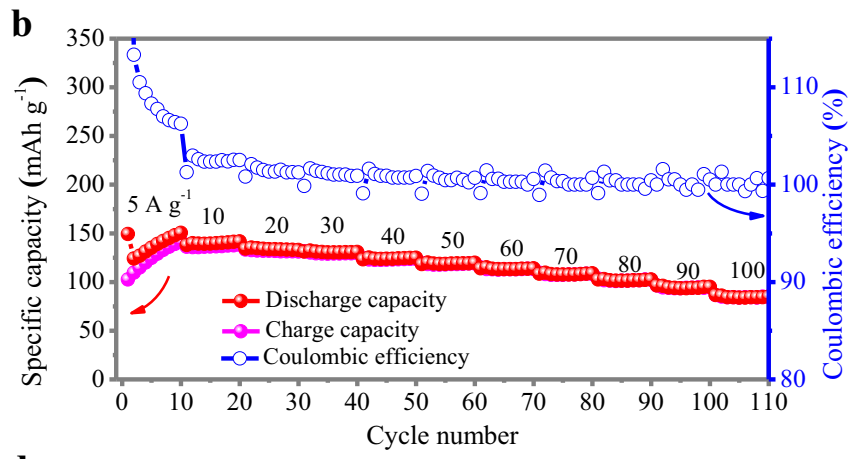

d

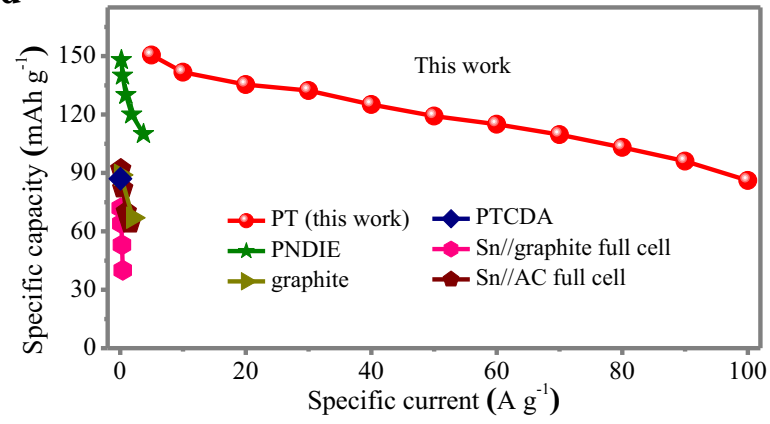


a

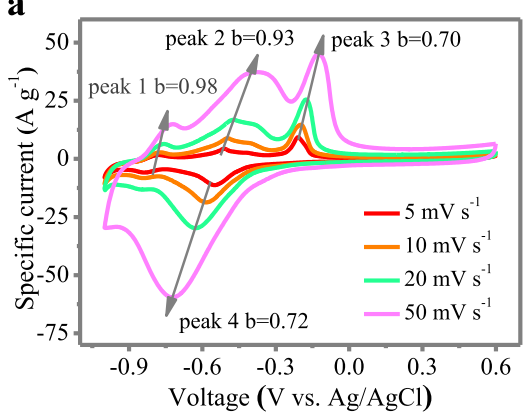

d

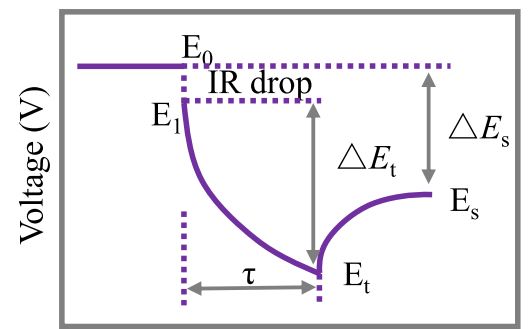

Time (s) b

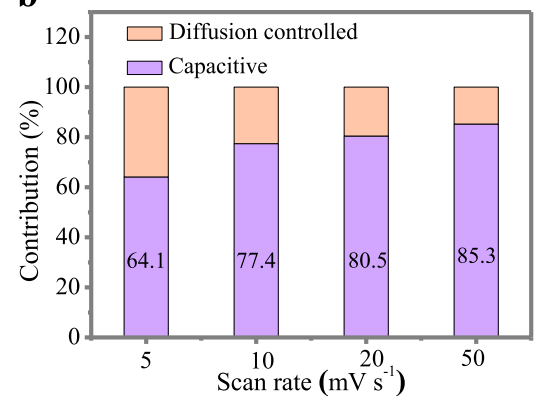

e

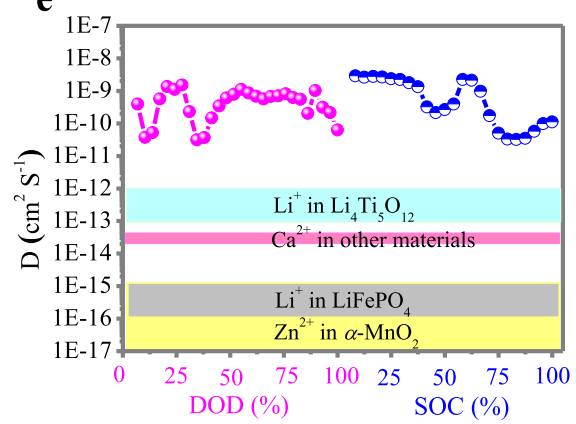

c

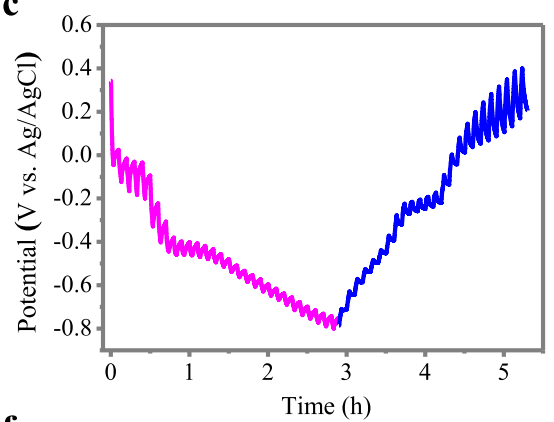

f

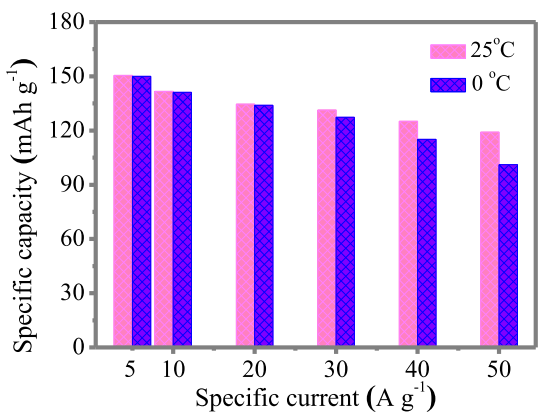

Fig. 3 Reaction kinetics of the PT anode in a three-electrode cell. a CV plots of PT anode in $1 \mathrm{M} \mathrm{CaCl}_{2}$ at $\mathrm{scanning}$ rates from 5 to $50 \mathrm{mV} \mathrm{s}^{-1}$. $\mathbf{b}$

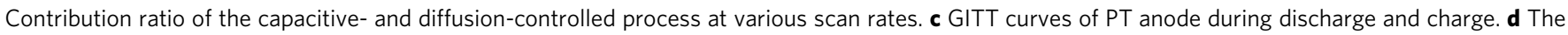
key parameters for diffusion coefficient calculation. e The calculated $\mathrm{Ca}^{2+}$ ion diffusion coefficient during discharging and charging process and comparison with other systems. $\mathbf{f}$ Specific capacities of $\mathrm{PT}$ in $1 \mathrm{M} \mathrm{CaCl}_{2}$ at room temperature and $0^{\circ} \mathrm{C}$.

recording the $\mathrm{CV}$ curves at various scan rates. With an increasing scan rate from 5 to $50 \mathrm{mV} \mathrm{s}^{-1}$, the $\mathrm{CV}$ curves displayed similar shapes with gradually magnified specific currents (Fig. 3a). In principle, the current response of an electrode material can be correlated to the scan rate according to Eq. $1^{34,35}$ :

$$
i=a v^{b}
$$

Where $\mathrm{a}$ and $\mathrm{b}$ are constants. By plotting $\log (i)$ vs. $\log (v)$ (Supplementary Fig. 3), the b values for the four marked redox peaks in Fig. 3 a are calculated to be $0.98,0.93,0.70$, and 0.72 . The distinct $b$ values indicate varied reaction kinetics for each peak. The capacitive contribution at each scan rate is further quantified according to previous reports ${ }^{36,37}$. At $10 \mathrm{mV} \mathrm{s}^{-1}$, the capacitive effect contributed $77.4 \%$ of the total capacity (i.e., the shaded area in Supplementary Fig. 4). Moreover, the contribution ratio increases progressively with the scan rate. It plays a leading role in the total capacity at high scan rates of $50 \mathrm{mV} \mathrm{s}^{-1}$ (Fig. 3b), signifying a high-power capability of PT materials due to their flexible structure with $1 \mathrm{D}$ channels for efficient $\mathrm{Ca}^{2+}$ ion diffusion.

The effective diffusion of $\mathrm{Ca}^{2+}$ ions in organic PT crystals, which is a great challenge for CIBs due to the high charge density and the bulk size of $\mathrm{Ca}^{2+}$, was quantified using the galvanostatic intermittence titration technique (GITT) ${ }^{38,39}$. A series of current pulses followed by a relaxation process was applied to the PT anodes (Fig. 3c). The chemical diffusion coefficient $(D)$ of $\mathrm{Ca}^{2+}$ in the active material can be estimated according to Fig. $3 \mathrm{~d}$ and the following Eq. $2^{38,39}$ :

$$
\mathrm{D}=\frac{4}{\pi \tau}\left(\frac{\mathrm{mV}_{m}}{\mathrm{MS}}\right)^{2}\left(\frac{\Delta E_{\mathrm{s}}}{\Delta E_{\tau}}\right)^{2}
$$

Where $\tau$ is the constant current pulse duration (s); $m, M$, and $V_{\mathrm{M}}$ are the mass $(\mathrm{g})$, molar mass $\left(338.3 \mathrm{~g} \mathrm{~mol}^{-1}\right)$ and molar volume $\left(222.9 \mathrm{~cm}^{3} \mathrm{~mol}^{-1}\right)$ of $\mathrm{PT}$, respectively; $\mathrm{S}$ is the electrodeelectrolyte interface area (taken as the geometric area of the electrode, $\left.\sim 1 \mathrm{~cm}^{2}\right) ; \Delta E_{\mathrm{S}}$ is the steady-state potential change (V) by the current pulse, and $\Delta E_{\mathrm{t}}$ is the potential change $(\mathrm{V})$ during the constant current pulse after eliminating the $\mathrm{iR}$ drop.

The calculated diffusion coefficient of the $\mathrm{Ca}^{2+}$ ions $(D)$ in the PT anode during discharging and charging is in the range of $10^{-8}-10^{-11} \mathrm{~cm}^{2} \mathrm{~S}^{-1}$ (Fig. 3e), which is significantly higher than that of $\mathrm{Li}^{+}$in $\mathrm{LiFePO}_{4}\left(10^{-14}-10^{-16} \mathrm{~cm}^{2} \mathrm{~S}^{-1}\right.$ as determined by GITT $\left.{ }^{40}\right)$ and $\mathrm{Li}_{4} \mathrm{Ti}_{5} \mathrm{O}_{12}\left(10^{-11}-10^{-12} \mathrm{~cm}^{2} \mathrm{~S}^{-1}\right.$ as determined by potentiostatic intermittent titration technique ${ }^{41}$ and $10^{-12}-10^{-13} \mathrm{~cm}^{2} \mathrm{~S}^{-1}$ as determined by $\left.\mathrm{CV}^{42}\right), \mathrm{Zn}^{2+}$ in $\alpha-\mathrm{MnO}_{2}$ $\left(10^{-15}-10^{-17} \mathrm{~cm}^{2} \mathrm{~S}^{-1} \text { as determined by GITT) }\right)^{43}, \mathrm{Ca}^{2+}$ in other materials (e.g., $\mathrm{Ca}^{2+}$ in Ni-based metal-organic compound, $5.3 \times$ $10^{-14} \mathrm{~cm}^{2} \mathrm{~S}^{-1}$ as determined by electrochemical impedance spectroscopy) $)^{44}$. The high apparent diffusion coefficient of $\mathrm{Ca}^{2+}$ ions (D) in the PT anode can be ascribed to its weakly stacked layered structure with 1D molecular channels, which provides an efficient $\mathrm{Ca}^{2+}$ ion diffusion pathway, thus leading to enhanced reaction kinetics of $\mathrm{PT}$ during the electrochemical reaction process.

To gain a comprehensive understanding of the electrochemical behavior of the PT material, the capacities of PT measured at $0{ }^{\circ} \mathrm{C}$ and room temperature $\left(\sim 25^{\circ} \mathrm{C}\right)$ were compared (Fig. 3f). According to the Arrhenius equation, achieving superior electrochemical performance at low temperatures is very difficult since the reaction rate is significantly reduced ${ }^{45}$. Notably, the PT anode underwent only very slight capacity degradation, with $84.8 \%$ capacity retention at a high specific current of $50 \mathrm{Ag}^{-1}$, signifying good reaction kinetics of this aromatic organic crystal in the low-temperature range.

We now turn our attention to scrutinizing the detailed charge storage chemistry of PT crystals in aqueous solutions. For aqueous zinc-based batteries, the co-insertion of protons $\left(\mathrm{H}^{+}\right.$or $\left.\mathrm{H}_{3} \mathrm{O}^{+}\right)$ with $\mathrm{Zn}^{2+}$ is widely reported due to the smaller size of protons ${ }^{27,46-48}$. However, the role of protons during the storage of $\mathrm{Ca}^{2+}$ remains undiscernible in aqueous CIBs. To clarify the effect of protons in this CIB system, the CV curve of the PT anode with 
a

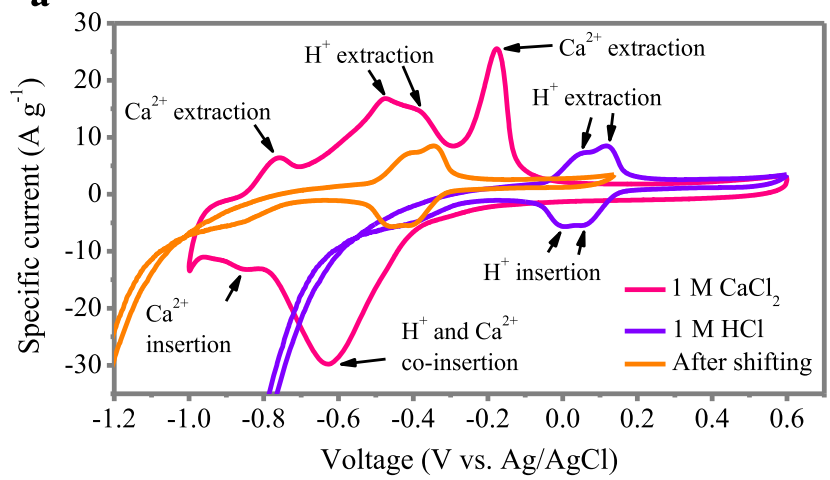

c
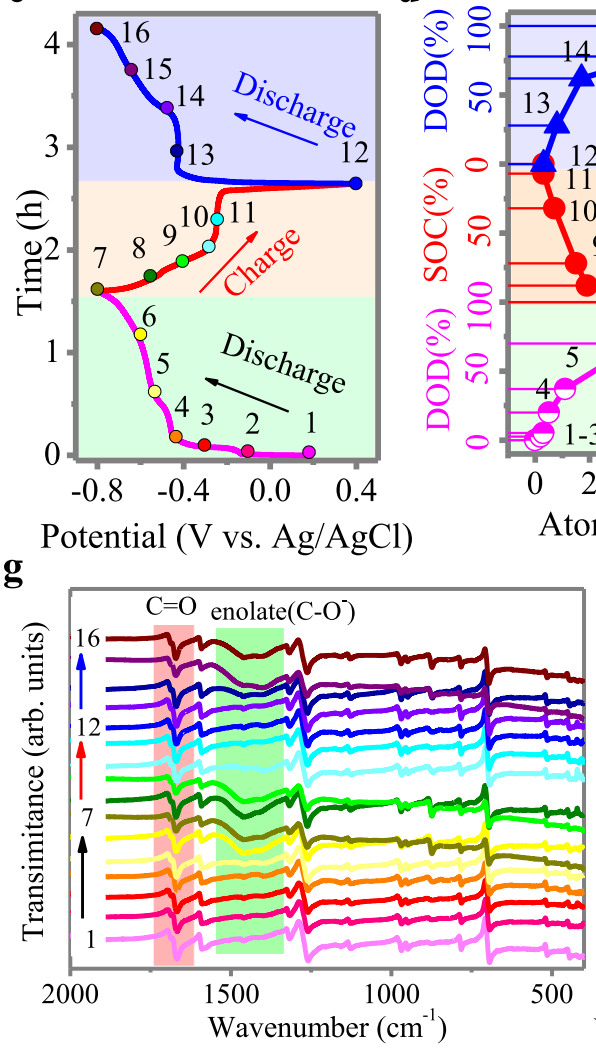

g

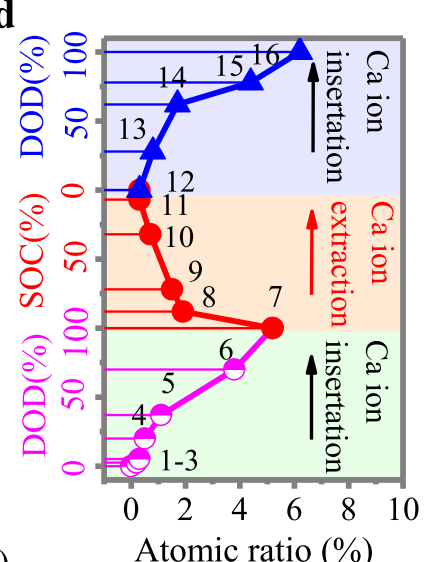

b

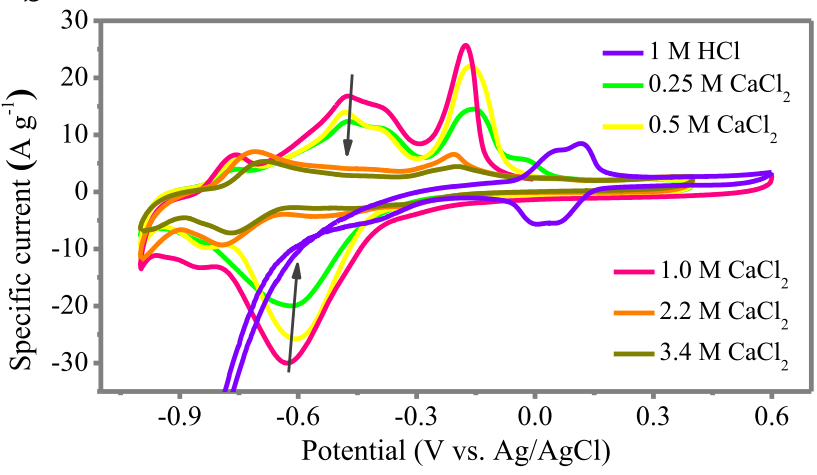

f

e
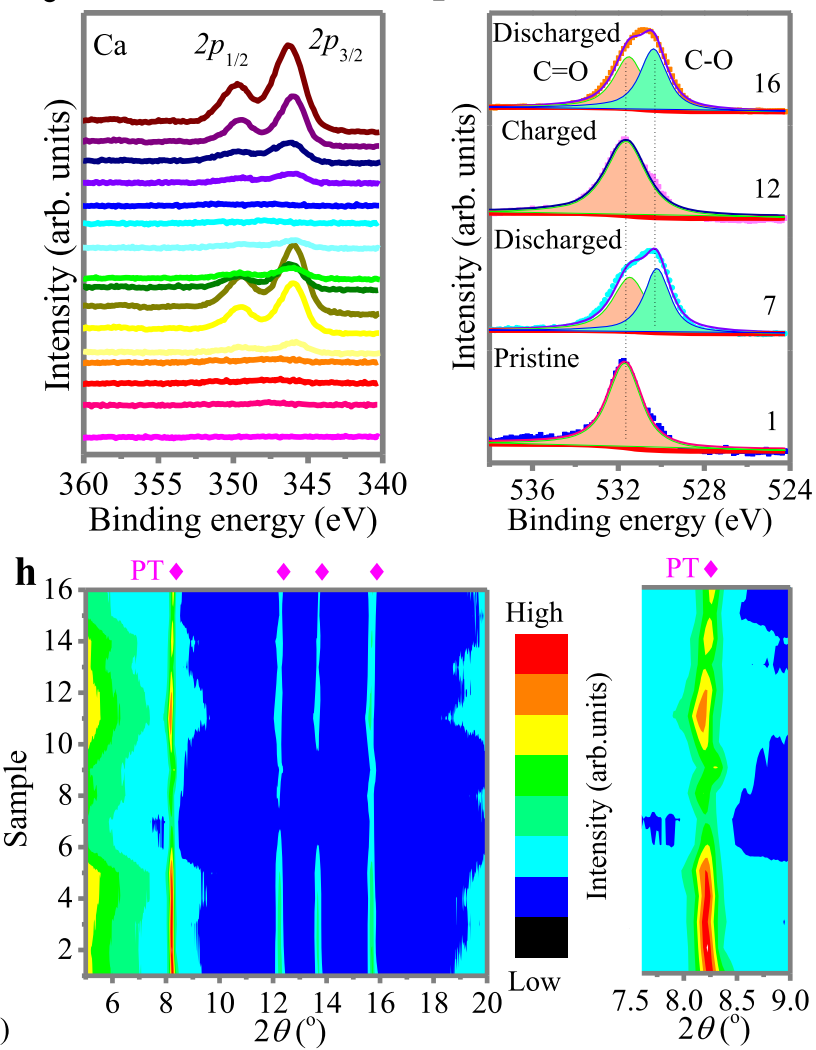

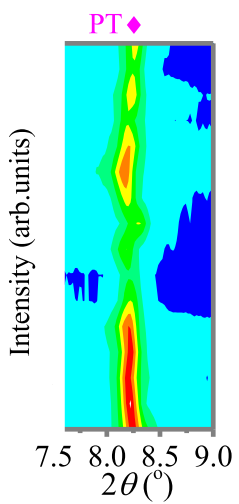

Fig. 4 Mechanistic study on the Ca-ion storage in PT anode. a CV curves of PT anode in $1 \mathrm{M} \mathrm{CaCl}_{2}$ and $1 \mathrm{M} \mathrm{HCl}$ at $20 \mathrm{mV} \mathrm{s}^{-1}$. The orange line represents corresponding $\mathrm{CV}$ curves in a $\mathrm{pH}=7.8$ solution, calculated based on the Nernst equation. $\mathbf{b} \mathrm{CV}$ curves of $\mathrm{PT}$ anode in different $\mathrm{CaCl}{ }_{2}$ solutions and in $1 \mathrm{M}$ $\mathrm{HCl}$ at $20 \mathrm{mV} \mathrm{s}^{-1}$. c Initial discharge-charge curve and the second discharge curve of PT anode under a specific current of $0.1 \mathrm{~A} g \mathrm{~g}^{-1}$. $\mathrm{Various}$ ex situ tests were conducted at the marked points. d Atomic concentration of Ca at marked points by XPS. e Ex situ XPS spectrum of Ca $2 p$. $\mathbf{f}$ O $1 s$ XPS spectra at selected points. $\mathbf{g}$ Ex situ FTIR. h Ex situ XRD.

$1 \mathrm{M} \mathrm{CaCl} 2$ electrolyte $(\mathrm{pH}=7.8)$ was compared with that in highly concentrated $\mathrm{H}^{+}$solutions (i.e., $1 \mathrm{M} \mathrm{HCl}$ electrolyte, $\mathrm{pH}=$ 1.0) (Fig. 4a, Supplementary Fig. 5a). In the $\mathrm{HCl}$ electrolyte, the $\mathrm{PT}$ anode presents two reduction peaks at $0.06 \mathrm{~V}$ and $0 \mathrm{~V}$ vs. Ag/ $\mathrm{AgCl}$ and two oxidization peaks at $0.05 \mathrm{~V}$ and $0.12 \mathrm{~V}$ vs. $\mathrm{Ag} / \mathrm{AgCl}$, respectively, which is related to proton uptake/release with the carbonyl groups of PT. The corresponding $\mathrm{CV}$ curves for a $\mathrm{pH}=$ 7.8 solution (the same $\mathrm{pH}$ value as $1 \mathrm{M} \mathrm{CaCl}_{2}$ aqueous solution) can be obtained by shifting the $\mathrm{CV}$ curves measured for the PT anode in $1 \mathrm{M} \mathrm{HCl}$ according to the Nernst equation (Supplementary Methods for Calculation based on Nernst Equation) ${ }^{30}$. The location of the two oxidization peaks after shifting partially overlapped with the oxidization peaks at $-0.47 \mathrm{~V}$ and $-0.38 \mathrm{~V}$ vs. $\mathrm{Ag} / \mathrm{AgCl}$ measured in $1 \mathrm{M} \mathrm{CaCl}_{2}$ electrolyte, suggesting that the proton participated in the storage process of $\mathrm{Ca}^{2+}$ ions in the PT anode. More importantly, proton participation is also observed in similar aromatic organic molecular crystals, such as PQ (Supplementary Fig. 6), suggesting that the findings of this work apply to other aromatic organic materials. By comparing the area under the two oxidization peaks at $-0.47 \mathrm{~V}$ and $-0.38 \mathrm{~V}$ vs. $\mathrm{Ag} / \mathrm{AgCl}$ with the total anodic scan, it is calculated that $\sim 49 \%$ of the total capacity is contributed by proton uptake. Moreover, the specific capacity of the PT anode in $1 \mathrm{M} \mathrm{HCl}$ was also measured (Supplementary Fig. 7), corresponding to $\sim 43 \%$ of the $150.5 \mathrm{mAh} \mathrm{g}^{-1}$ achieved in $1 \mathrm{M} \mathrm{CaCl}_{2}$. These results collectively suggest that $\sim 40-50 \%$ of the total capacity comes from proton uptake.

During the reduction process, $\mathrm{H}^{+}$seems to be inserted before or during the insertion of $\mathrm{Ca}^{2+}$ since only two reduction peaks are observed (i.e., $-0.85 \mathrm{~V}$ and $-0.63 \mathrm{~V}$ vs. $\mathrm{Ag} / \mathrm{AgCl}$ ) and the insertion potential of $\mathrm{H}^{+}$after shifting (i.e., $-0.46 \mathrm{~V}$ vs. $\mathrm{Ag} / \mathrm{AgCl}$ ) 
is on the right shoulder of the first reduction peak. This supposition was verified by comparing the $\mathrm{CV}$ curves of the PT anode measured in the $\mathrm{CaCl}_{2}$ electrolyte of different concentrations (Fig. 4b). As the concentration of $\mathrm{CaCl}_{2}$ electrolyte increases from $1 \mathrm{M}$ to $3.4 \mathrm{M}$, a significant decrease in the current response in the two oxidization peaks at $-0.47 \mathrm{~V},-0.38 \mathrm{~V}$ vs. $\mathrm{Ag} / \mathrm{AgCl}$, and a reduction peak at $-0.63 \mathrm{~V}$ vs. $\mathrm{Ag} / \mathrm{AgCl}$ is observed, mainly due to the decrease in proton numbers in the highly concentrated electrolyte. This result verifies that the oxidization peaks at -0.47 $\mathrm{V}$ and $-0.38 \mathrm{~V}$ vs. $\mathrm{Ag} / \mathrm{AgCl}$ correspond to proton extraction. Furthermore, without the contribution from protons, the insertion of $\mathrm{Ca}^{2+}$ negligibly proceeds as indicated by the sharp decline in the reduction peak at $-0.63 \mathrm{~V}$. Therefore, the reduction peak at $-0.63 \mathrm{~V}$ contains a significant proportion of proton insertion. This claim was further confirmed by measuring the CV curves the PT anode in ethylene glycol (EG)-based organic electrolytes (Supplementary Fig. 5b). The PT anode shows no pronounced redox peaks in the EG-based $1 \mathrm{M} \mathrm{CaCl}_{2}$ solution due to the absence of proton. In contrast, a significant increase in specific current and the presence of redox peaks are observed after $\mathrm{H}_{2} \mathrm{O}$ is added to the nonaqueous electrolyte, confirming the important role of protons during the insertion of $\mathrm{Ca}^{2+}$, although the $\mathrm{pH}$ value of the $\mathrm{CaCl}_{2}$ solution is slightly alkaline (Supplementary Fig. 5a).

To better understand the structural evolution of PT crystal during the co-insertion of protons and $\mathrm{Ca}^{2+}$ ions, various ex situ tests, including FTIR, X-ray photoelectron spectroscopy (XPS), and X-ray diffraction (XRD) were performed with the PT anodes at the initial two charge-discharge cycles, as shown in Fig. 4c. XPS explorations powerfully demonstrate the reversible uptake of $\mathrm{Ca}^{2+}$ during discharge and its removal after recharging (Fig. 4d, e). Even after Ar ion etching at 10 and $20 \mathrm{~nm}$ off, the discharged PT anode still exhibits in-depth XPS peaks of Ca $2 p$ (Supplementary Fig. 8), verifying Ca bulk storage in the PT anodes. Notably, the concentration of $\mathrm{Ca}$ ions at the initial stage of the discharge process is very low and begins to increase after the discharge potential falls below $-0.46 \mathrm{~V}$ vs. Ag/ $\mathrm{AgCl}$ (point 4) (Fig. 4d), coinciding with the assumption that $\mathrm{Ca}^{2+}$ is inserted after proton insertion (i.e., $-0.46 \mathrm{~V}$ vs. $\mathrm{Ag} / \mathrm{AgCl}$ after shifting).

In addition, XPS O $1 s$ spectra reveal the appearance of the $\mathrm{C}-\mathrm{O}$ peak $(530.3 \mathrm{eV})$ after discharging and its disappearance after charging (Fig. 4f), which coincides with the sustained coordination of $\mathrm{H}^{+}$and $\mathrm{Ca}^{2+}$ on the carbonyl groups of PT. The invertible conversion process is also verified by ex situ FTIR (Fig. $4 \mathrm{~g}$ ). In the FTIR spectra, upon discharging, the stretching vibration of carbonyl groups $(-\mathrm{C}=\mathrm{O})$ at approximately $1668 \mathrm{~cm}^{-1}$ is gradually weakened, while an additional and broad band centered at $\sim 1460 \mathrm{~cm}^{-1}$ is strengthened, indicating the conversion of carbonyl groups $(\mathrm{C}=\mathrm{O})$ to enolate groups $\left(\mathrm{C}-\mathrm{O}^{-}\right)^{23,49}$. During the following charging process, the carbonyl group peaks return to their initial state, while the peaks of enolate groups gradually become weaker. These XPS and FTIR results support the chemical adsorption mechanistic assumption, where the cations adsorb to the negatively charged oxygen atoms upon electrochemical reduction of the carbonyl groups and desorb reversibly during reverse oxidation. Moreover, compared with the traditional intercalation-/deintercalation-based energy storage mechanism, this enolation reaction of quinone $(-\mathrm{C}=\mathrm{O})$ to quinone salts $(-\mathrm{C}-\mathrm{O}-\mathrm{M})$ is beneficial for sustaining the high structural stability of PT materials during repeated cycling. As a consequence, the ex situ XRD data reveal that the most intriguing structural change in PT upon discharging is the slight reduction in peak intensity (Fig. 4h) due to morphological changes, as revealed by transmission electron microscopy (TEM) and scanning electron microscopy (SEM) in a subsequent section. Upon decalcification, the peak intensities are partially restored. No extra peaks are observed. The PT anodes were subjected to 10 discharge/charge cycles at $0.1 \mathrm{~A} \mathrm{~g}^{-1}$ and demonstrate good crystallinity (Supplementary Fig. 9). Furthermore, the XRD profiles of the PT anodes subjected to a high-rate test at $100 \mathrm{Ag}^{-1}$ (Supplementary Fig. 10) and cycling test at $30 \mathrm{Ag}^{-1}$ were also obtained (Supplementary Fig. 11), which showed well-retained characteristic peaks, indicating the robust structural stability of PT materials during repeated cycling.

The morphology variation of PT during the discharge and charge process is given in Supplementary Figs. 12, 13. The freshly prepared electrode consists of small conductive carbon and a large bulk of PT (Supplementary Fig. 12b). Upon discharge, this bulk PT converts to highly homogeneous fibers of $\sim 1-2 \mu \mathrm{m}$ in length and $\sim 200 \mathrm{~nm}$ in diameter (Supplementary Fig. 12c), signifying a morphology evolution process. When the voltage is discharged to $-0.46 \mathrm{~V}$ vs. $\mathrm{Ag} / \mathrm{AgCl}$ (point 4), spheroidal particles with a large dimension of $\sim 500 \mathrm{~nm}$ begin to form, matching well with the XPS data showing that the content of $\mathrm{Ca}$ begins to increase after point 4 . With the discharge process ongoing, an increasing number of spheroidal particles are formed and randomly distributed around the fibers (Supplementary Figs. 12d, g, 13), which are quite different from the initial PT materials. Upon charging, these spheroids gradually disappear, with only fibershaped PT remaining in the electrode (Supplementary Fig. 12e, f). The formation and disappearance of these spheroidal particles are highly reversible during the discharge and charge process. A TEM characterization of both fibers and spheroids was conducted (Fig. 5, Supplementary Fig. 14), Surprisingly, Ca was not observed in the fibers as suggested by electron energy-loss spectroscopy (EELS) and TEM-energy-dispersive spectroscopy (EDS) mapping images (Supplementary Fig. 14), but was concentrated on the spheroids formed in the discharged state (Fig. 5a-c), with a weight percent of $\mathrm{C}: \mathrm{Ca}=76.3: 23.7$ by EELS. Inductively coupled plasma-mass spectrometry (ICP-MS) analysis was also used to quantify the Ca concentration in the whole PT anode, which was measured to be $16.9 \mathrm{~g} \mathrm{~kg}^{-1}$ (Supplementary Table 3). The highresolution TEM image reveals the crystalline nature of the Cainserted products and lattice fringes with an interlayer space of $0.272 \mathrm{~nm}$ (Fig. 5d). Fast Fourier transform was conducted on the selected area (marked by yellow frame), and the yielded diffraction pattern can be well indexed to the triclinic PT phase (Fig. 5e). The corresponding SAED pattern over a broad area displays diffraction rings from the unreacted PT phase $(0.32,0.255$, and $0.162 \mathrm{~nm})$ and the Ca-inserted PT phase $(0.272 \mathrm{~nm})$ (Fig. $5 \mathrm{f})$, which is consistent with the XRD measurement that the Cainserted phase adopts the same crystal structure as fresh PT. Therefore, it is assumed that the PT anode experienced a gradual morphology evolution from the large bulk form to nanofibres and finally to nanosphere aggregates during calcium uptake, but the underlying reason for this morphological evolution needs further investigation.

The accommodation of $\mathrm{Ca}^{2+}$ in the PT crystal is quite complicated because of the divalent nature of $\mathrm{Ca}^{2+}$, which is not well documented in literature. This is because the storage of one $\mathrm{Ca}^{2+}$ is expected to cause the enolation of at least two carbonyl groups. This is very different from monovalent ions (e.g., $\mathrm{Li}^{+}, \mathrm{Na}^{+}$, or $\mathrm{K}^{+}$), where one carbonyl group binds one cation. Moreover, there is a high possibility that these carbonyl groups come from adjacent PT molecules to suppress the strong electrostatic interaction. Theoretical calculations based on density functional theory (DFT) were conducted to simulate the possible extent of $\mathrm{Ca}^{2+}$ storage in PT crystals. Individual geometries of the PT molecule and its crystal structure were optimized at the Perdew-Burke-Ernzerhof (PBE) functional. The corresponding lattice parameters match well with the experimental values (Supplementary Table 1). Then, the molecular electrostatic potential (MESP) was calculated to 

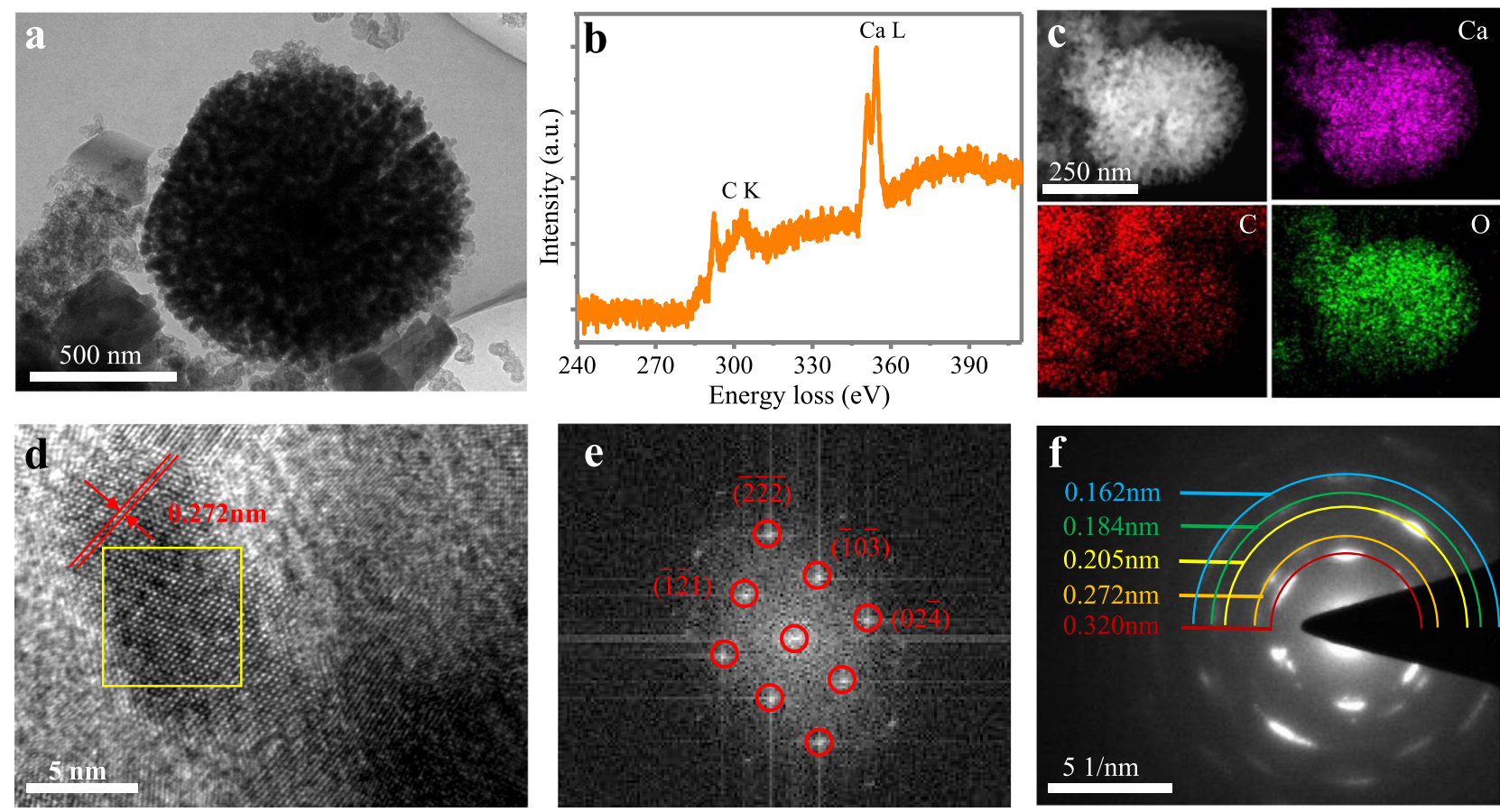

Fig. 5 Ex situ TEM characterization of the Ca-inserted PT electrode. a Low magnification TEM image. b EELS spectrum. c EDS mapping image of Ca, C and O. $\mathbf{d}$ high magnification TEM image. e The FFT image on the area shown in the yellow frame of (d) and (f) the SAED pattern.

obtain further insight into the exact site of $\mathrm{Ca}$ ion uptake (Fig. 6a). Generally, the more positive MESP (blue region) sites represent the nucleophilic center, whereas the more negative MESP areas (red region) prefer electrophilic reactions ${ }^{50}$. According to the MESP mapping results, a pronounced variation in electron distribution is observed between the carbonyl units and the aromatic rings of $\mathrm{PT}$, which favors an electrostatic interaction between the molecules. The regions near the carbonyls of PT have more negative MESP values, suggesting that the carbonyls are more favorable for cation ion uptake, which shows good consistency with the XPS O1s and ex situ FTIR spectra ${ }^{28}$. According to the energy-band structure and density of states (Fig. 6b), the PT crystal is an indirect-gap material with a band gap of $1.77 \mathrm{eV}$, falling within the semiconductor range.

The diffusion of $\mathrm{Ca}$ ions is a primary task in the stacked and layered-like structure research field. The $\mathrm{Ca}$ migration pathway for a $\mathrm{Ca}$ atom confined within the PT crystal were investigated by the climb image nudged elastic band (CI-NEB) method (Fig. 6c), which contributes to finding the rules of calcium diffusion. The multimodal curve reflects the existence of several metastable states. The energy barriers for Ca diffusion and bond breaking/ making were in the range of $0.18-0.35 \mathrm{eV}$ as facilitated by the carbonyl units, and the migration path of Ca closely resembled an irregular spiral channel (Fig. $6 c$ and Supplementary Movie 1). The cell with a PT:Ca ratio of 4:1 possesses an overall volume of $\sim 0.3732 \mathrm{~nm}^{3}$ after full relaxation (Fig. $6 \mathrm{~d}$ ), which is very close to the fresh PT cell volume $\left(0.3703 \mathrm{~nm}^{3}\right)$, due to the efficient planar packing arrangement of the relaxed molecules.

According to Fig. $6 c$, four representative metastable states and their equilibrium configurations were further studied (Fig. 7). The inserted $\mathrm{Ca}$ ions tend to remain between the stacked layers of organic molecules, whereas at the interstitial space of the $1 \mathrm{D}$ channels (Fig. 7, Supplementary Fig. 15). Although the accommodation of one divalent $\mathrm{Ca}^{2+}$ is expected to necessitate the enolation of two carbonyl groups, the $\pi-\pi$ stacking nature of the crystal causes the negative charge from the enolates to be delocalized through the stacks. Therefore, each $\mathrm{Ca}$ ion tends to be stabilized by four adjacent carbonyls to generate the optimal equilibrium configuration (the ground state configuration, State IV in Fig. 7b and Supplementary Fig. 15). The theoretical study on Ca transfer confirms that PT crystals with $\pi-\pi$ stacked layers and 1D nanochannels show a proper scope of Ca-binding energies and easy ion transportation, allowing the fast storage of calcium ions in the nanochannels of PT crystals and contributing to the improvement of electrochemical performance.

To understand the performance of PT as a potential anode, a full aqueous CIB is necessary. We synthesized a high-voltage Prussian blue analogue (i.e., $\mathrm{KCoFe}(\mathrm{CN})_{6} \cdot x \mathrm{H}_{2} \mathrm{O}$ ) for the cathode material by a facile and simple coprecipitation route previously described $^{51}$. The phase purity and crystal structure of the asobtained $\mathrm{KCoFe}(\mathrm{CN})_{6} \cdot x \mathrm{H}_{2} \mathrm{O}$ are confirmed by $\mathrm{XRD}$, which adopts a 3D cyanide-bridged architecture with a space group of Fm3m (Supplementary Fig. 16a). The as-prepared KCoFe $(\mathrm{CN})_{6} \cdot x \mathrm{H}_{2} \mathrm{O}$ exhibits a single pair of well-defined redox peaks at $0.42 / 0.53 \mathrm{~V}$ vs. $\mathrm{Ag} / \mathrm{AgCl}$ and one additional reduction peak at $-0.13 \mathrm{~V}$ vs. $\mathrm{Ag} / \mathrm{AgCl}$ in the first $\mathrm{CV}$ scan at $0.5 \mathrm{mV} \mathrm{s}^{-1}$ (Supplementary Fig. 16b). Notably, the reduction peak at $-0.13 \mathrm{~V}$ vs. $\mathrm{Ag} / \mathrm{AgCl}$ is caused by the reduction in dissolved $\mathrm{O}_{2}$ in the aqueous electrolyte and is only present in the first CV scan (Supplementary Fig. 17). The redox peaks at $0.42 / 0.53 \mathrm{~V}$ vs. $\mathrm{Ag} / \mathrm{AgCl}$ are ascribed to the two redox couples of $\mathrm{Co}(\mathrm{III}) / \mathrm{Co}(\mathrm{II})$ and $\mathrm{Fe}$ (III) $/ \mathrm{Fe}$ (II) in the as-prepared materials. The GCD profiles of the stabilized $\mathrm{KCoFe}(\mathrm{CN})_{6}$ present one pair of stable operational voltage plateaus (Supplementary Fig. 16c), which is consistent with the $\mathrm{CV}$ plots. The rate performance is also explored, displaying specific capacities of $94.9,80.7,75.7,69.9$, and $66.8 \mathrm{mAh} \mathrm{g}$ -1 at the specific currents of $0.2,0.5,1,2$, and $5 \mathrm{~A} \mathrm{~g}^{-1}$, respectively. When the current is reduced to $1 \mathrm{Ag}^{-1}$, the specific capacity immediately recovers with their reversal (Supplementary Fig. 16d). The cycling stability is examined at $2 \mathrm{~A} \mathrm{~g}^{-1}$, delivering a capacity retention of $83.7 \%$ after 1000 cycles (Supplementary Fig. 16e). This achieved capacity and cycle ability far exceeds $\mathrm{Fe}_{4}\left[\mathrm{Fe}(\mathrm{CN})_{6}\right]_{3}$ and $\mathrm{KFe}_{0.35} \mathrm{Mn}_{0.65} \mathrm{Fe}(\mathrm{CN})_{6} \quad\left(59.5 \mathrm{mAh} \mathrm{g}^{-1}\right.$ and $60 \mathrm{mAh} \mathrm{g}^{-1}$ at $1 \mathrm{~A} \mathrm{~g}^{-1}$ (Supplementary Fig. 18), respectively, and 
$\mathbf{a}$

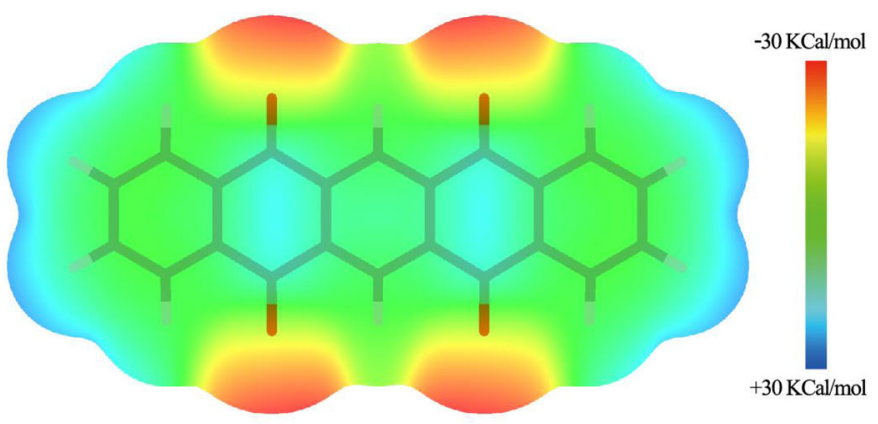

c

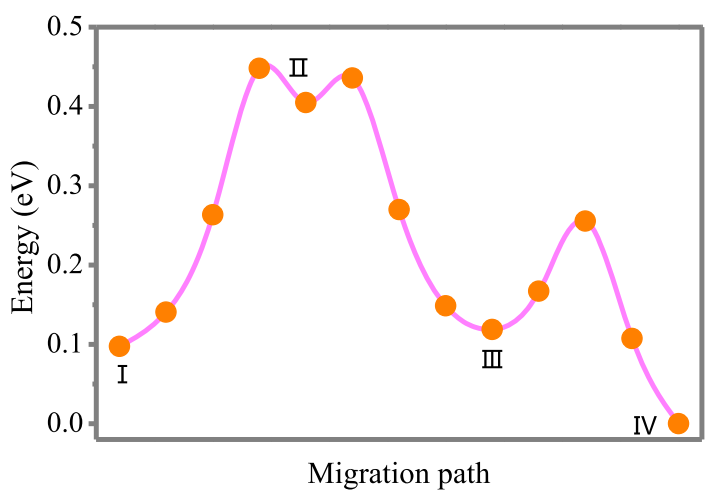

b

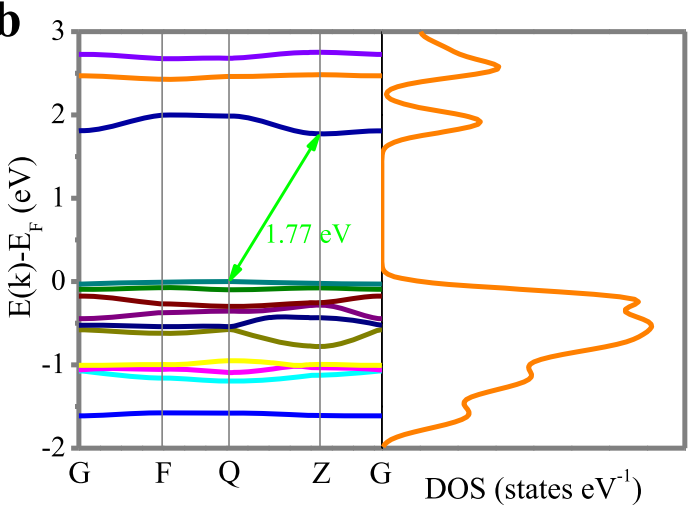

d

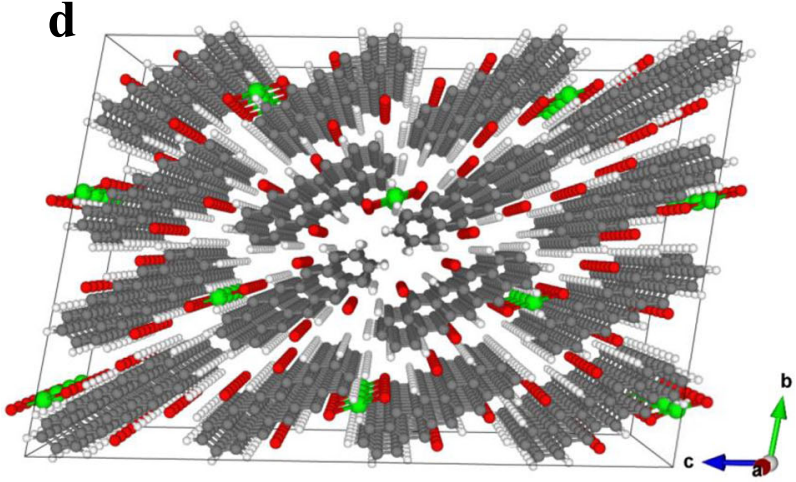

Fig. 6 Theoretical calculations of the Ca-ion storage in a PT crystal. a The MESP-mapped molecular van der Waals surface of PT. $\mathbf{b}$ the band structure and DOS of PT. $\mathbf{c}$ The diffusion pathway of a Ca ion confined within the channel of PT crystal. d Perspective view of a $(4 \times 4 \times 10)$ Ca-inserted PT supercell with a PT: Ca concentration of 4:1.
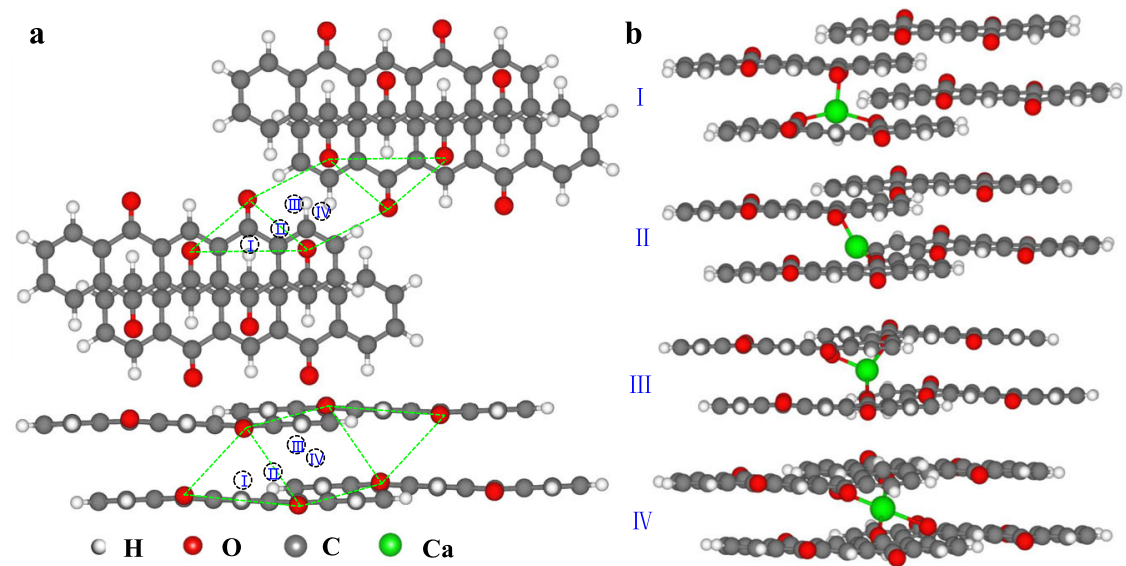

Fig. 7 Spatial distribution of the Ca ions confined within the PT crystal channels. a The top view. The dotted circle represents the relevant equilibrium position for $\mathrm{Ca}$, the green dotted line shows the distance between the adjacent $\mathrm{O}$ atoms. $\mathbf{b}$ The front view.

that reported for CIBs cathode materials thus far (Supplementary Table 2), including $\mathrm{Ca}_{\mathrm{x}} \mathrm{CuHCF}\left(42 \mathrm{mAh} \mathrm{g}^{-1} @ 12 \mathrm{C}\right)^{32}, \mathrm{KNiFe}$ $(\mathrm{CN})_{6}\left(50 \mathrm{mAh} \mathrm{g}^{-1} @ 0.2 \mathrm{C}\right)^{52}, \mathrm{~K}_{\mathrm{x}} \mathrm{NiFe}(\mathrm{CN})_{6}\left(50 \mathrm{mAh} \mathrm{g}^{-1} @ 25 \mu \mathrm{A}\right.$ $\left.\mathrm{cm}^{-2}\right)^{33}, \mathrm{NH}_{4} \mathrm{~V}_{4} \mathrm{O}_{10}\left(61 \mathrm{mAh} \mathrm{g}^{-1} @ 1 \mathrm{Ag}^{-1}\right)^{53}, \mathrm{Mg}_{0.25} \mathrm{~V}_{2} \mathrm{O}_{5} \cdot \mathrm{H}_{2} \mathrm{O}$

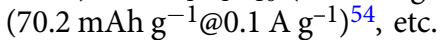

Considering the two described materials, we successfully assembled a full aqueous $\mathrm{Ca}$-ion cell by utilizing $\mathrm{Ca}^{2+}$ ion storage in the PT anode and insertion chemistry in the $\mathrm{KCoFe}(\mathrm{CN})_{6}$ cathode (Fig. 8a and Supplementary Fig. 19). Considering the better rate capability of $\mathrm{PT}$ compared to $\mathrm{KCoFe}(\mathrm{CN})_{6}$, a mass ratio of PT: $\mathrm{KCoFe}(\mathrm{CN})_{6}=1: 2.5$ is utilized. This full cell process can be concretely described by the individual CV curves of the cathode and anode. As seen from Fig. 8b, the PT anode and PBA cathode invariably work in opposite potential directions, leading to a maximum cell voltage of $2.1 \mathrm{~V}$. The typical CV profiles of the full cell produce three pairs of concessive reduction/oxidization peaks (Fig. 8c). The shape of the CV curves is well maintained with small polarization even at high scan rates of $100 \mathrm{mV} \mathrm{s}^{-1}$. Then, a GCD test was performed on the full cell, generating specific capacities of $179.5,129.6,110.8,99.6,92.2,82.5$, $75.6 \mathrm{mAh} \mathrm{g}^{-1}$ and $72.2 \mathrm{mAh} \mathrm{g}_{\mathrm{PT}}{ }^{-1}$ at 2, 5, 10, 15, 20, 30, 40, and $50 \mathrm{~A} \mathrm{~g}^{-1}$ based on the PT mass (Fig. 8d), corresponding to 51.3, $37.0,31.7,28.5,26.3,23.6,21.6$, and $20.6 \mathrm{mAh} \mathrm{g}^{-1}$ based on the total mass of $\mathrm{PT}$ and $\mathrm{KCoFe}(\mathrm{CN})_{6}$, respectively, proving good 
a

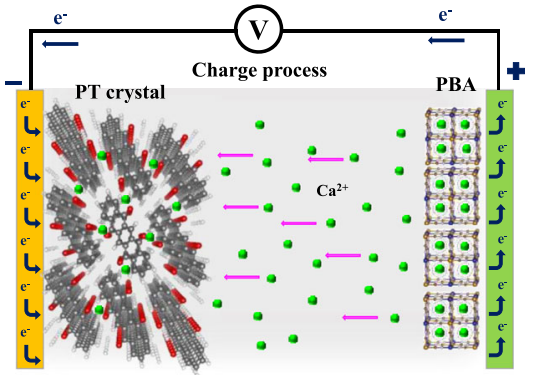

b

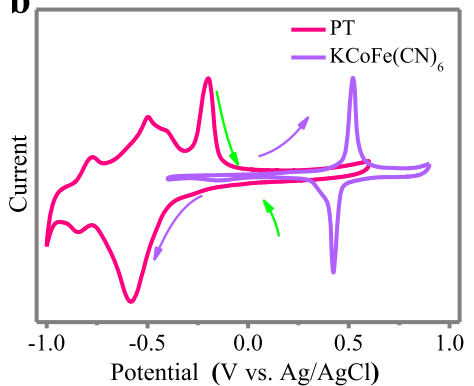

d 350

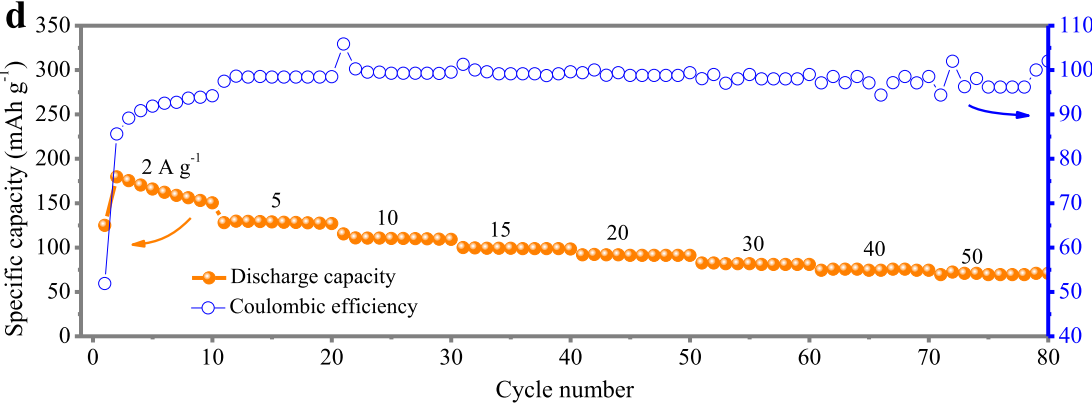

f

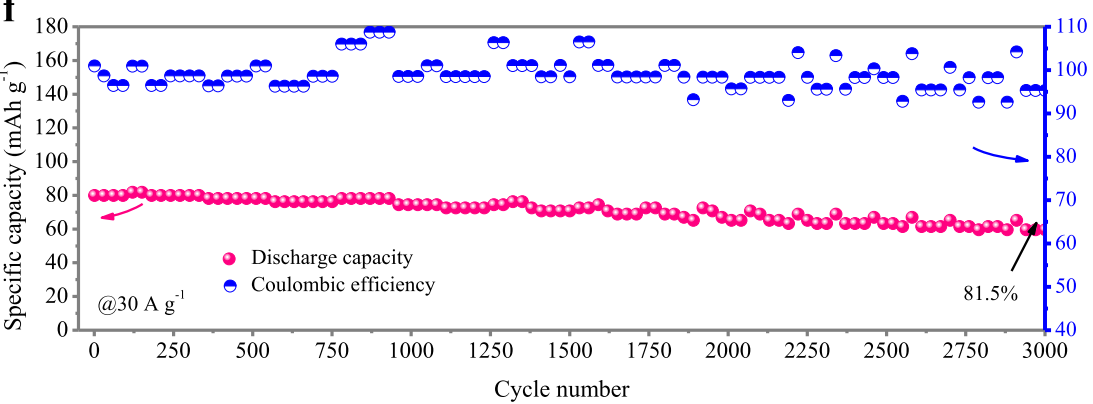

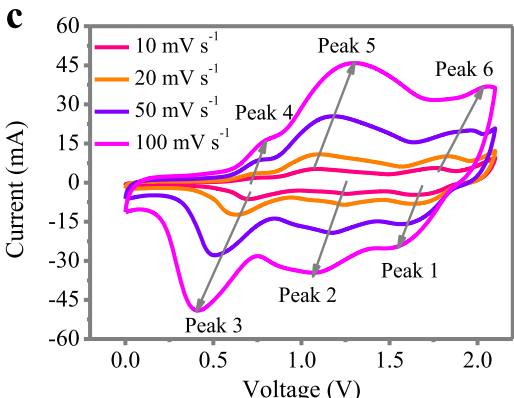

$\mathbf{e}$
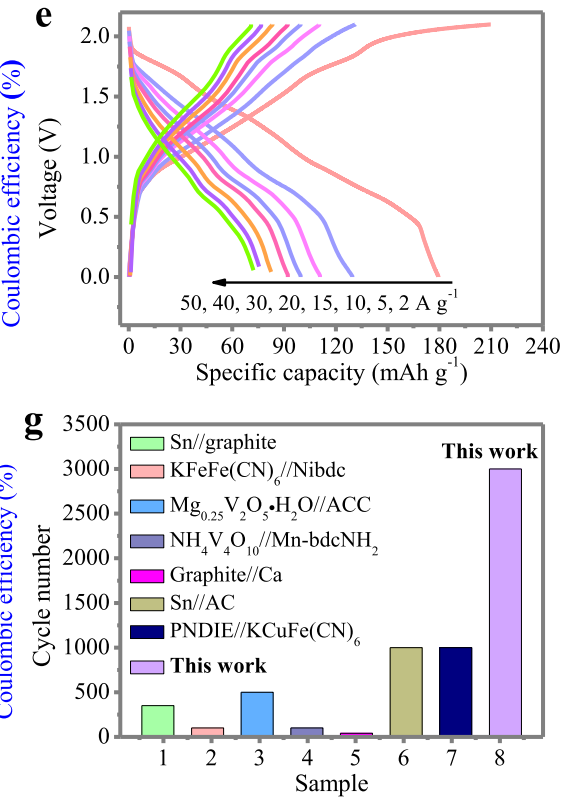

Fig. 8 Full aqueous Ca-ion cell based on PT anode and $\mathbf{K C o F e}(\mathbf{C N})_{6}$ PBA cathode. a Schematic illustration of the reaction mechanism of the PT//PBA full cell. $\mathbf{b}$ Comparison of the CV curves of PT anode and PBA cathode. $\mathbf{c}$ The CV curves for the full cell at scan rates of $10-100 \mathrm{mV} \mathrm{s}{ }^{-1}$. $\mathbf{d}$ The rate capability at different specific currents. e the GCD curves at different specific currents. $\mathbf{f}$ Cycle performance at $30 \mathrm{Ag}^{-1}$. $\mathbf{g}$ Cycle performance comparison with literature. See Supplementary Table 2 for reported data in literature.

rate capability. Notably, the relatively low Coulombic efficiency at $2 \mathrm{~A} \mathrm{~g}^{-1}$ is caused mainly by the gradual activation of the PT anode; it rapidly increases to $\sim 100 \%$ at subsequent specific currents. In addition, the operational voltage $(2.1 \mathrm{~V})$ and specific capacity are comparable to those of CIBs using an organic electrolyte, although aqueous batteries have a limited voltage window. The corresponding GCD curves are illustrated in Fig. 8e, revealing a sloping voltage profile with $0-2.1 \mathrm{~V}$. The differential capacity $(\mathrm{dQ} / \mathrm{dV})$ curve exhibits distinct redox peaks at $2 \mathrm{Ag}^{-1}$ (Supplementary Fig. 20). Correspondingly, a maximum specific energy of $200.4 \mathrm{Wh} \mathrm{kg}^{-1}$ can be achieved at a specific power of $1861 \mathrm{~W} \mathrm{~kg}^{-1}$ based on the mass of PT, which corresponds to 57.3 Wh kg-1 based on the total mass of both PT and $\mathrm{KCoFe}(\mathrm{CN})_{6}$. The self-discharge performance of the full cell was evaluated by standing for $24 \mathrm{~h}$ at $100 \%$ state of charge after the initial 20 cycles at $1 \mathrm{~A} \mathrm{~g}^{-1}$, followed by discharging to $0 \mathrm{~V}$. As shown in Supplementary Fig. 21, the capacity of the full cell decreased to $77 \%$ of its original discharge capacity after resting for $24 \mathrm{~h}$ and quickly recovered its original capacity in the subsequent cycles. The selfdischarge behavior can be suppressed by electrode modification, electrolyte modulation and separator modification, etc ${ }^{55-57}$. Finally, charge-discharge cycling at a specific current of $30 \mathrm{~A} \mathrm{~g}^{-1}$ was carried out, showing a capacity retention of $\sim 81.5 \%$ after 3000 cycles (Fig. 8f), which is among the longest reported for CIB systems (both aqueous and nonaqueous) (Fig. $8 \mathrm{~g}$ and
Supplementary Table 2), including Sn//graphite ${ }^{18}$, Sn//Activated carbon $(\mathrm{AC})^{17}, \mathrm{PNDIE} / / \mathrm{KCuFe}(\mathrm{CN})_{6}{ }^{24}, \mathrm{KFeFe}(\mathrm{CN})_{6} / / \mathrm{Ni}$-based metal-organic compound ${ }^{44}, \quad \mathrm{NH}_{4} \mathrm{~V}_{4} \mathrm{O}_{10} / /$ manganese 2aminoterephthalate $\left.(\mathrm{Mn}-\mathrm{bdcNH})_{2}\right)^{53}, \quad \mathrm{Mg}_{0.25} \mathrm{~V}_{2} \mathrm{O}_{5} \cdot \mathrm{H}_{2} \mathrm{O} / /$ Activated carbon cloth $(\mathrm{ACC})^{54}$, graphite $/ / \mathrm{Ca}^{19}$, etc.

In summary, the high charge density of divalent $\mathrm{Ca}^{2+}$ poses strong electrostatic interaction with the hosting lattice, resulting in the difficult $\mathrm{Ca}^{2+}$ storage. Moreover, the large ionic radius of $\mathrm{Ca}^{2+}(0.099 \mathrm{~nm})$ leads to sluggish $\mathrm{Ca}^{2+}$ ion diffusion, making the reversible and fast storage of divalent $\mathrm{Ca}^{2+}$ highly challenging. We report an aromatic organic molecular crystal PT as a highrate CIB anode. The long-range crystallinity and $1 \mathrm{D}$ diffusion channels considerably improve the $\mathrm{Ca}$ ion diffusion kinetics. Many benefits realized through these unique properties. The PT anode displayed a high specific capacity of $150.5 \mathrm{~mA} \mathrm{~h} \mathrm{~g}^{-1}$ at $5 \mathrm{~A} \mathrm{~g}^{-1}$, a capacity of $86.1 \mathrm{~mA} \mathrm{~h} \mathrm{~g}^{-1}$ at a high current of $100 \mathrm{~A}$ $\mathrm{g}^{-1}$, and stable cycling performance. A diffusion coefficient of $\mathrm{Ca}^{2+}$ ions in the PT anode is revealed by the GITT technique to be as high as $10^{-8}-10^{-11} \mathrm{~cm}^{2} \mathrm{~S}^{-1}$. Ex situ XPS, FTIR, and XRD collectively confirmed highly reversible and proton-assisted $\mathrm{Ca}^{2+}$ ion storage chemistry, accompanied by robust structural stability. Theoretical calculations suggest that the $\mathrm{Ca}$ ion migration path closely resembles an irregular spiral channel and that the most stable configuration is realized by the coordination of one $\mathrm{Ca}$ ion with four carbonyls in adjacent PT molecules. A full Ca-ion cell is 
then capitalized with a $\mathrm{KCoFe}(\mathrm{CN})_{6} \bullet \mathrm{xH}_{2} \mathrm{O}$ cathode, achieving a high voltage of $2.1 \mathrm{~V}$ and demonstrating the great promise of the as-developed PT as a potential anode material for aqueous ion batteries.

\section{Methods}

Electrode preparation. 5,7,12,14-Pentacenetetrone (PT, 95\% purity) was purchased from Macklin reagent Co., LTD. To prepare the PT anode, the PT material, acetylene black and polyvinylidene fluoride (PVDF) binder were mixed homogeneously in solids under stirring for $10 \mathrm{~min}$ in a weight ratio of 6:3:1. Then $\mathrm{N}$-methyl-2pyrrolidinone (NMP) solvent was added into the above mixture and stirred for $4 \mathrm{~h}$ to form a homogeneous slurry, which was then coated on a carbon cloth substrate (CeTech, Co., LTD) and dried under vacuum at $90^{\circ} \mathrm{C}$ for $10 \mathrm{~h}$. The carbon cloth substrate was treated in $\mathrm{O}_{2}$ plasma for $10 \mathrm{~min}$ before use. The $\mathrm{KCoFe}(\mathrm{CN})_{6} \cdot x \mathrm{H}_{2} \mathrm{O}$ cathode was prepared using the same slurry coating method except that a weight ratio of 6:2:2 was employed. The active material mass loading of the PT anode and the $\mathrm{KCoFe}(\mathrm{CN})_{6} \cdot \mathrm{H}_{2} \mathrm{O}$ cathode are $\sim 1.5 \mathrm{mg} \mathrm{cm}^{-2}$ and $\sim 3.7 \mathrm{mg} \mathrm{cm}^{-2}$, respectively.

Cell fabrication. Three-electrode beaker cells were first assembled with asprepared PT or $\mathrm{KCoFe}(\mathrm{CN})_{6}$ electrode $(1 \times 1 \mathrm{~cm})$ as working electrode, $\mathrm{Pt}$ as the counter electrode and $\mathrm{Ag} / \mathrm{AgCl}$ as the reference electrode (Supplementary Fig. 1). The distance between each electrodes are around $1 \mathrm{~cm}$. The electrolyte employed was $8 \mathrm{~mL}$ aqueous $\mathrm{CaCl}_{2}(99.9 \%$ metals basis, Aladdin) solution with different concentration $(0.25 \mathrm{M}, 0.5 \mathrm{M}, 1 \mathrm{M}, 2.2 \mathrm{M}$, and $3.4 \mathrm{M}$, respectively). Then, beakertype full Ca-ion cells were assembled with PT as anodes and $\mathrm{KCoFe}(\mathrm{CN})_{6}$ as cathodes in a mass ratio of 1:2.5 (anode/cathode) and $8 \mathrm{~mL} 1 \mathrm{M} \mathrm{CaCl}_{2}$ aqueous solution as electrolyte (Supplementary Fig. 19).

Electrochemical characterization. Both CV experiment and GCD measurements was carried out on a CHI760E electrochemical workstation. GITT was performed using a battery testing system (LAND CT2001A). A series of current pulses of $200 \mathrm{~mA} \mathrm{~g}^{-1}$ was applied on PT electrodes for $2 \mathrm{~min}$ followed by a 4 min relaxation process. The specific currents and specific capacities were calculated based on the mass of the active materials (i.e., PT or $\mathrm{KCoFe}(\mathrm{CN})_{6} \cdot x \mathrm{H}_{2} \mathrm{O}$, respectively). The specific energy $(\mathrm{E}, \mathrm{W} \mathrm{h} \mathrm{kg}-1)$ and corresponding specific power $\left(\mathrm{P}, \mathrm{W} \mathrm{kg}{ }^{-1}\right)$ values of the full Ca-ion cell were calculated as follows:

$$
\begin{gathered}
E=\frac{\int I V(t) \mathrm{dt}}{3.6 m} \\
P=\frac{3600 E}{t}
\end{gathered}
$$

where, $I(\mathrm{~A})$ is the applied current, $V(\mathrm{~V})$ is the voltage of the cell, $t(\mathrm{~s})$ is the corresponding discharge time, and $m(\mathrm{~g})$ is weight of electrode.

Materials characterization. The structure and phase composition were characterized by X-ray diffraction measurement (XRD, Rigaku D/max 2500/PC using CuKa radiation) and the diffraction data was collected at a step mode over the angular range of $5-60^{\circ}$. The microstructure and morphologies were characterized with field emission scanning electron microscopy (FE-SEM, HITACH S4800, 10 $\mathrm{kV}, 5 \mathrm{~mA}$ ) and transmission electron microscopy (TEM, TECNAI G2 F30, accelerating voltage of $200 \mathrm{kV}$ ) equipped with an energy-dispersive X-ray (EDX) spectroscopy (Oxford INCA) and electron energy-loss spectroscopy (EELS, Gatan). XPS analysis was measured in a PHI 5000 VersaProbe II equipped with $\mathrm{Al} \mathrm{Ka}$ radiation and an $\mathrm{Ar}$ ion cluster sputtering gun. Attenuated Total Reflection Flourier transformed Infrared (ATR-FTIR) spectroscopy was conducted on a Thermo Scientific Nicolet iS 50 spectrometer. ICP-MS analysis was tested with Agilent ICP-MS 7700.

Density functional theory calculations. DFT calculations with the PBE functional were performed by using the Vienna ab initio Simulation Package ${ }^{58,59}$. The electron-ion interactions were presented by the frozen core all-electron projector augmented wave pseudopotentials, and generalized gradient approximation of the electron exchange-correlation functional was adopted ${ }^{60,61}$. Periodic $(3 \times 2 \times 1)$ supercell ${ }^{28}$ was constructed to reveal the mechanism of calcium storage. All atoms were unfixed during the relaxation except the lattice parameters and basis vectors. The Kohn-Sham valence states were expanded in a plane-wave basis set with a kinetic cutoff energy of $500 \mathrm{eV}$, and geometries were optimized until the energy convergence criterion of $10^{-4} \mathrm{eV}$ and the maximum threshold force of $10^{-2} \mathrm{eV} \AA$ ${ }^{-1}$ were fulfilled. K-point sampling was performed by the Monkhorst-Pack scheme, with sampling grids of $(3 \times 3 \times 3)^{62}$. To account for the weak dispersion interactions, these functionals were used in combination with the DFT-D2 correction 63 The diffusion barrier of calcium ion in the channel of PT crystal was calculated based on the climb image nudged elastic band (CI-NEB) method ${ }^{64}$. A MonkhorstPack $3 \times 3 \times 3$ mesh was used to sample the reciprocal space and the calculation was considered to be converged when the residual force components on each atom were below $0.02 \mathrm{eV} \AA^{-1}$.

Reporting summary. Further information on research design is available in the Nature Research Reporting Summary linked to this article.

\section{Data availability}

The data that support the findings of this study are available from the corresponding author upon reasonable request.

Received: 3 October 2020; Accepted: 18 March 2021; Published online: 23 April 2021

\section{References}

1. Yan, C. et al. Architecting a stable high-energy aqueous al-ion battery. J. Am Chem. Soc. 142, 15295-15304 (2020).

2. Chao, D. et al. Roadmap for advanced aqueous batteries: from design of materials to applications. Sci. Adv. 6, eaba4098 (2020)

3. Guo, Y. et al. A rechargeable Al- $\mathrm{N}_{2}$ battery for energy storage and highly efficient $\mathrm{N}_{2}$ fixation. Energy Environ. Sci. 13, 2888-2895 (2020).

4. Liang, G. et al. Initiating hexagonal $\mathrm{MoO}_{3}$ for superb-stable and fast $\mathrm{NH}_{4}{ }^{+}$ storage based on hydrogen bond chemistry. Adv. Mater. 32, 1907802 (2020).

5. Gummow, R. J., Vamvounis, G., Kannan, M. B. \& He, Y. Calcium-ion batteries: current state-of-the-art and future perspectives. Adv. Mater. 30, 1801702 (2018).

6. Xie, J., Zhou, Z. \& Wang, Y. Metal- $\mathrm{CO}_{2}$ batteries at the crossroad to practical energy storage and $\mathrm{CO}_{2}$ recycle. Adv. Funct. Mater. 30, 1908285 (2020).

7. Arroyo-de Dompablo, M. E., Ponrouch, A., Johansson, P. \& Palacín, M. R Achievements, challenges, and prospects of calcium batteries. Chem. Rev. 120 6331-6357 (2019).

8. Ponrouch, A., Frontera, C., Bardé, F. \& Palacín, M. R. Towards a calciumbased rechargeable battery. Nat. Mater. 15, 169-172 (2016).

9. Forero-Saboya, J. et al. Understanding the nature of the passivation layer enabling reversible calcium plating. Energy Environ. Sci. 13, 3423-3431 (2020).

10. Li, Z., Fuhr, O., Fichtner, M. \& Zhao-Karger, Z. Towards stable and efficient electrolytes for room-temperature rechargeable calcium batteries. Energy Environ. Sci. 12, 3496-3501 (2019).

11. Shyamsunder, A., Blanc, L. E., Assoud, A. \& Nazar, L. F. Reversible calcium plating and stripping at room temperature using a borate salt. ACS Energy Lett. 4, 2271-2276 (2019).

12. Aurbach, D., Skaletsky, R. \& Gofer, Y. The electrochemical behavior of calcium electrodes in a few organic electrolytes. J. Electrochem. Soc. 138, 3536-3545 (2019)

13. Wang, D. et al. Plating and stripping calcium in an organic electrolyte. Nat. Mater. 17, 16-20 (2018).

14. Chen, T., Sai Gautam, G. \& Canepa, P. Ionic transport in potential coating materials for Mg batteries. Chem. Mater. 31, 8087-8099 (2019).

15. Rong, Z. et al. Materials design rules for multivalent ion mobility in intercalation structures. Chem. Mater. 27, 6016-6021 (2015).

16. Canepa, P. et al. High magnesium mobility in ternary spinel chalcogenides. Nat. Commun. 8, 1759 (2017).

17. Wu, N. et al. A calcium-ion hybrid energy storage device with high capacity and long cycling life under room temperature. Adv. Energy Mater. 9, 1803865 (2019).

18. Wang, M. et al. Reversible calcium alloying enables a practical roomtemperature rechargeable calcium-ion battery with a high discharge voltage. Nat. Chem. 10, 667-672 (2018)

19. Park, J. et al. Stable and high-power calcium-ion batteries enabled by calcium intercalation into graphite. Adv. Mater. 32, 1904411 (2020).

20. Han, C., Zhu, J., Zhi, C. \& Li, H. The rise of aqueous rechargeable batteries with organic electrode materials. J. Mater. Chem. A 8, 15479-15512 (2020).

21. Han, C. et al. Organic quinones towards advanced electrochemical energy storage: recent advances and challenges. J. Mater. Chem. A 7, 23378-23415 (2019).

22. Huang, J., Dong, X., Guo, Z. \& Wang, Y. Progress of organic electrodes in aqueous electrolyte for energy storage and conversion. Angew. Chem. Int. Ed. 132, 18478-18489 (2020)

23. Rodríguez-Pérez, I. A. et al. Mg-Ion battery electrode: an organic solid's Herringbone structure squeezed upon $\mathrm{Mg}$-ion insertion. J. Am. Chem. Soc. 139, 13031-13037 (2017).

24. Gheytani, S. et al. An aqueous Ca-ion battery. Adv. Sci. 4, 1700465 (2017)

25. Liu, N. et al. Building high rate capability and ultrastable dendrite-free organic anode for rechargeable aqueous zinc batteries. Adv. Sci. 7, 2000146 (2020). 
26. Ma, L. et al. Initiating a wearable solid-state Mg hybrid ion full battery with high voltage, high capacity and ultra-long lifespan in air. Energy Storage Mater. 31, 451-458 (2020).

27. Sun, W. et al. $\mathrm{Zn} / \mathrm{MnO}_{2}$ battery chemistry with $\mathrm{H}^{+}$and $\mathrm{Zn}^{2+}$ coinsertion. J. Am. Chem. Soc. 139, 9775-9778 (2017).

28. Käfer, D., El Helou, M., Gemel, C. \& Witte, G. Packing of planar organic molecules: interplay of van der Waals and electrostatic interaction. Cryst. Growth Des. 8, 3053-3057 (2008).

29. Tang, M. et al. Tailoring p-conjugated systems: From p-p Stacking to highrate-performance organic cathodes. Chem 4, 2600-2614 (2018).

30. Wang, Y. et al. Binding zinc ions by carboxyl groups from adjacent molecules toward long-life aqueous zinc-organic batteries. Adv. Mater. 32, 2000338 (2020).

31. Liu, H., Zhang, G., Zhou, Y., Gao, M. \& Yang, F. One-step potentiodynamic synthesis of poly(1,5-diaminoanthraquinone)/reduced graphene oxide nanohybrid with improved electrocatalytic activity. J. Mater. Chem. A 1, 13902-13913 (2013).

32. Adil, M. et al. Practical aqueous calcium-ion battery full-cells for future stationary storage. Acs Appl. Mater. Interfaces 12, 11489-11503 (2020).

33. Tojo, T., Sugiura, Y., Inada, R. \& Sakurai, Y. Reversible calcium ion batteries using a dehydrated prussian blue analogue cathode. Electrochim. Acta 207, 22-27 (2016).

34. He, P. et al. Layered VS2 nanosheet-based aqueous $\mathrm{Zn}$ ion battery cathode. Adv. Energy Mater. 7, 1601920 (2017).

35. $\mathrm{Li}, \mathrm{H}$. et al. $\mathrm{MoS}_{2}$ nanosheets with expanded interlayer spacing for rechargeable aqueous Zn-ion batteries. Energy Storage Mater. 19, 94-101 (2018).

36. Wang, J., Polleux, J., Lim, J. \& Dunn, B. Pseudocapacitive contributions to electrochemical energy storage in $\mathrm{TiO}_{2}$ (anatase) nanoparticles. J. Phys. Chem. C. 111, 14925-14931 (2007).

37. Han, C., Zhang, T., Li, J., Li, B. \& Lin, Z. Enabling flexible solid-state Zn batteries via tailoring sulfur deficiency in bimetallic sulfide nanotube arrays. Nano Energy 77, 105165 (2020).

38. Wei, T., Li, Q., Yang, G. \& Wang, C. Highly reversible and long-life cycling aqueous zinc-ion battery based on ultrathin $\left(\mathrm{NH}_{4}\right)_{2} \mathrm{~V}_{10} \mathrm{O}_{25} \cdot 8 \mathrm{H}_{2} \mathrm{O}$ nanobelts. J. Mater. Chem. A 6, 20402-20410 (2018).

39. $\mathrm{Ni}$, Q. et al. 3D Electronic channels wrapped large-sized $\mathrm{Na}_{3} \mathrm{~V}_{2}\left(\mathrm{PO}_{4}\right)_{3}$ as flexible electrode for sodium-ion batteries. Small 14, 1702864 (2018).

40. Prosini, P. P., Lisi, M., Zane, D. \& Pasquali, M. Determination of the chemical diffusion coefficient of lithium in $\mathrm{LiFePO}_{4}$. Solid State Ion. 148 45-51 (2002).

41. Rho, Y. H. \& Kanamura, K. $\mathrm{Li}^{+}$ion diffusion in $\mathrm{Li}_{4} \mathrm{Ti}_{5} \mathrm{O}_{12}$ thin film electrode prepared by PVP sol-gel method. J. Solid State Chem. 177, 2094-2100 (2004).

42. $\mathrm{Li}$, B. et al. Facile synthesis of $\mathrm{Li}_{4} \mathrm{Ti}_{5} \mathrm{O}_{12} / \mathrm{C}$ composite with super rate performance. Energy Environ. Sci. 5, 9595-9602 (2012).

43. Lee, B. et al. Elucidating the intercalation mechanism of zinc ions into a$\mathrm{MnO}_{2}$ for rechargeable zinc batteries. Chem. Commun. 51, 9265-9268 (2015).

44. Vo, T. N., Hur, J. \& Kim, I. T. Enabling high performance calcium-ion batteries from prussian blue and metal-organic compound materials. ACS Sustain. Chem. Eng. 8, 2596-2601 (2020).

45. Waldmann, T., Wilka, M., Kasper, M., Fleischhammer, M. \& WohlfahrtMehrens, M. Temperature dependent ageing mechanisms in lithium-ion batteries-a post-mortem study. J. Power Sources 262, 129-135 (2014).

46. Tie, Z., Liu, L., Deng, S., Zhao, D. \& Niu, Z. Proton insertion chemistry of a zinc-organic battery. Angew. Chem. Int. Ed. 59, 4920-4924 (2020).

47. Pan, $\mathrm{H}$. et al. Reversible aqueous zinc/manganese oxide energy storage from conversion reactions. Nat. Energy 1, 16039 (2016).

48. Kundu, D. et al. Organic cathode for aqueous $\mathrm{Zn}$-ion batteries: taming a unique phase evolution toward stable electrochemical cycling. Chem. Mater 30, 3874-3881 (2018).

49. Guo, Z. et al. An environmentally friendly and flexible aqueous zinc battery using an organic cathode. Angew. Chem. 130, 11911-11915 (2018).

50. Zhao, Q. et al. High-capacity aqueous zinc batteries using sustainable quinone electrodes. Sci. Adv. 4, eaao1761 (2018).

51. Ma, L. et al. Achieving high-voltage and high-capacity aqueous rechargeable zinc ion battery by incorporating two-species redox reaction. Adv. Energy Mater. 9, 1902446 (2019).

52. Wang, R. Y., Wessells, C. D., Huggins, R. A. \& Cui, Y. Highly reversible open framework nanoscale electrodes for divalent ion batteries. Nano Lett. 13, 5748-5752 (2013).

53. Vo, T. N., Kim, H., Hur, J., Choi, W. \& Kim, I. T. Surfactant-assisted ammonium vanadium oxide as a superior cathode for calcium-ion batteries. J. Mater. Chem. A 6, 22645-22654 (2018).
54. $\mathrm{Xu}$, X. et al. Bilayered $\mathrm{Mg}_{0.25} \mathrm{~V}_{2} \mathrm{O}_{5} \cdot \mathrm{H}_{2} \mathrm{O}$ as a stable cathode for rechargeable Ca-ion batteries. ACS Energy Lett. 4, 1328-1335 (2019).

55. Wang, Z. et al. Unraveling and regulating self-discharge behavior of $\mathrm{Ti}_{3} \mathrm{C}_{2} \mathrm{~T}_{\mathrm{x}}$ MXene-based supercapacitors. ACS Nano 14, 4916-4924 (2020).

56. Ike, I. S., Sigalas, I. \& Iyuke, S. Understanding performance limitation and suppression of leakage current or self-discharge in electrochemical capacitors: a review. Phys. Chem. Chem. Phys. 18, 661-680 (2016).

57. Andreas, H. A. Self-Discharge in electrochemical capacitors: a perspective article. J. Electrochem. Soc. 162, A5047-A5053 (2015).

58. Kresse, G. \& Furthmüller, J. Efficiency of ab-initio total energy calculations for metals and semiconductors using a plane-wave basis set. Comp. Mater. Sci. 6 , 15-50 (1996).

59. Kresse, G. \& Furthmüller, J. Efficient iterative schemes for ab initio totalenergy calculations using a plane-wave basis set. Phys. Rev. B 54, 11169 (1996).

60. Perdew, J. P., Burke, K. \& Ernzerhof, M. Generalized gradient approximation made simple. Phys. Rev. Lett. 77, 3865-3868 (1996).

61. Kresse, G. \& Joubert, D. From ultrasoft pseudopotentials to the projector augmented-wave method. Phys. Rev. B 59, 1758-1775 (1999).

62. Monkhorst, H. J. \& Pack, J. D. Special points for Brillouin-zone integrations. Phys. Rev. B 13, 5188 (1976).

63. Grimme, S. Semiempirical GGA-type density functional constructed with a long-range dispersion correction. J. Comp. Chem. 27, 1787-1799 (2006).

64. Henkelman, G., Uberuaga, B. P. \& Jonsson, H. A climbing image nudged elastic band method for finding saddle points and minimum energy paths. $J$. Chem. Phys. 113, 9901-9904 (2000).

\section{Acknowledgements}

We acknowledge the financial support from Shenzhen Technical Plan Project (JCYJ20190808153609561), the National Key R\&D Program of China under Project 2019YFA0705104, National Natural Science Foundation of China (22005207).

\section{Author contributions}

Conceptualization: C.H., H.L., and C.Y.Z.; methodology: C.H., H.L., J.Z., and C.Y.Z.; investigation, C.H. and H.L.; computation: Y.L.; writing-original draft: C.H.; writingreview and editing, C.H., H.L. J.Z., Y.L., and C.Y.Z. H.L., and C.Y.Z. jointly supervised this work.

\section{Competing interests}

The author declares no competing interests.

\section{Additional information}

Supplementary information The online version contains supplementary material available at https://doi.org/10.1038/s41467-021-22698-9.

Correspondence and requests for materials should be addressed to H.L. or C.Z.

Peer review information Nature Communications thanks Sagar Mitra and the other, anonymous reviewer(s) for their contribution to the peer review of this work. Peer review reports are available.

Reprints and permission information is available at http://www.nature.com/reprints

Publisher's note Springer Nature remains neutral with regard to jurisdictional claims in published maps and institutional affiliations.

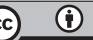

Open Access This article is licensed under a Creative Commons Attribution 4.0 International License, which permits use, sharing, adaptation, distribution and reproduction in any medium or format, as long as you give appropriate credit to the original author(s) and the source, provide a link to the Creative Commons license, and indicate if changes were made. The images or other third party material in this article are included in the article's Creative Commons license, unless indicated otherwise in a credit line to the material. If material is not included in the article's Creative Commons license and your intended use is not permitted by statutory regulation or exceeds the permitted use, you will need to obtain permission directly from the copyright holder. To view a copy of this license, visit http://creativecommons.org/ licenses/by/4.0/

(C) The Author(s) 2021 